\title{
PETROGRAFIA E PETROQUÍMICA DOS GRANULITOS DA REGIÃO DE ITABUNA - BAHIA
}

\author{
JOSÉ E. OLIVEIRA*, JOHILDO S.F. BARBOSA** e JOÃO B.A. ARCANJO*
}

\begin{abstract}
PETROGRAPHY AND PETROCHEMISTRY OF THE GRANULITES FROM THE ITABUNA REGION - BAHIA. The Early Proterozoic rocks of Itabuna region, southern Bahia, were separated into four main groups. The first one, the Ilhéus Complex (IC) is formed by bands of basic granulites with hornblende plus pyroxenes and mostly intermediate granulites (andesites and/or quartz diorites), these last ones with a high potassium calc-alkaline tendency. The second, the São José Complex (SJC) is essentially composed of basic (andesitic basalts and/or diorites) and intermediate granulites (andesites and/or quartz diorites) of low potassium calc-alkaline affiliation, but which include bands of garnet-bearing basic granulites (basalts and/or gabbros) of ocean floor or back-arc basin tholeiitic composition. The third group, the IbicaraíBuerarema Complex (IBC), and Rio Japu Complex, is made up mostly by intermediate granulites (andesitic basalts and/or diorites, andesites and/or quartz diorites, and dacites and/or tonalites) and acid granulites (rhyolites and/or trondhjemites), also with low potassium calc-alkaline tendency and which also exhibit bands of basic (basalts and/or gabbros) tholeiitic granulites of ocean floor or back-arc basin character. The fourth group is formed by plutonic bodies (monzodiorites, monzonites, syenites and granites) possibly derived from shoshonitic/alkaline magmas. These granulites may be correlated with those which occur to the north, where they before collision/obduction/deformation/metamorphism processes, as derived from a subduction zone near the Atlantic coastal region are considered, that generated arc/back-arc basin or active continental margin environments in the southeastern Bahia, during the Early Proterozoic.
\end{abstract}

Keywords: Granulite facies, Early Proterozoic, subduction zone, back-arc-basin, ocean floor basalts/gabbros.

RESUMO As rochas proterozóicas-inferiores da região de Itabuna, sul da Bahia, foram separadas em
quatco grupos principais. O primeiro, Complexo Ilhéus (Cl), é formado de bandas de granulitos básicos e
sobretudo de granulitos intermediários (andesitos e/ou quartzo-dioritos), estes últimos de tendência cálcio-
alcalina de alto potássio. O segundo, Complexo São José (CSJ), é composto essencialmente de granulitos
básicos (basaltos andesíticos e/ou dioritos) e intermediários (andesitos e/ou quartzo-dioritos), de filiação
cálcio-alcalina de baixo potássio, mas que mantêm inclusas bandas de granulitos básicos (basaltos e/ou gabros)
com granada, considerados como toleitos de fundo oceânico ou de bacia retro-arco. O terceiro, Complexo
Ibicaraí-Buerarema (CIB) e Complexo Rio Japu, é constituído, na maioria, de granulitos intermediários
(basaltos andesíticos e/ou dioritos, andesitos e/ou quartzo-dioritos e dacitos e/ou tonalitos), além de granulitos
ácidos (riolitos e/ou trondhjemitos,) também com tendência cálcio-alcalina de baixo potássio e que exibem
igualmente bandas de granulitos básicos basaltos e/ou gabros), toléiticos de fundo oceânico ou bacia pós-arco.
O quarto é formado de corpos plutônicos (monzodioritos, monzonitos, sienitos e granitos), possivelmente
oriundos de magmas shoshoníticos/alcalinos. Todos esses granulitos podem ser correlacionados com aqueles
situados mais ao norte, onde se considera que houve, antes dos processos de colisão/obducção/deformação/
metamorfismo, a produção de protólkos a partir de uma zona de subducção, mais próxima à região costeira
atlântica, o qual gerou arcos/bacia pós-arcos ou margem continental ativa na região sudeste da Bahia, parece
que durante o Proterozóico Inferior. Palavras-chave: Fácies granulito, Proterozóico Inferior, zona de subducção, bacia pós-arco, basaltos/gabros de fundo oceânico.

INTRODUÇÃO As rochas de alto grau metamórfico da região de Itabuna, motivo do presente trabalho, situam-se no embasamento do Cráton do São Francisco (Almeida 1977), no denominado Mobile Belt da Costa Atlântica (Costa \& Mascarenhas 1982), mais especificamente no Bloco Itabuna (Pedreira et al. 1975), também denominado Cinturão Itabuna (Figueiredo 1989) ou ainda Domínio da Costa Atlântica (Barbosa 1986).

Essas rochas granulíticas do sudeste da Bahia vem sendo estudadas desde o início dos anos setenta e, até meados dos anos oitenta, os seguintes trabalhos se destacaram: Sighinolfi (1970, 1971), Cordani (1973), Pedreira et al (1975), Sighinolfi \& Sakai (1977), Cordani \& lyer (1979), Brito Neves et al (1980), Sighinolfi et al (1981), Costa \& Mascarenhas (1982), Lima et al (1982), Oliveira \& Lima (1982), Oliveira et al (1982), Miranda et al (1982, 1985), Ribeiro (1982), lyer et al (1984) e Delhal \& Demaiffe (1985).
Entretanto, apesar dessas pesquisas terem contribuído consideravelmente, com importantes informações sobre a geologia da região, foram os trabalhos realizados a partir de 1985, focalizando principalmente a petroquímica, as condições termodinâmicas de formação dessas rochas e suas idades, que forneceram uma nova concepção sobre essa faixa granulítica. Assim, a partir daí, tornou-se possível definir parâmetros que permitiram, juntamente com a cartografia, estabelecer domínios geológicos inéditos até então e, ao mesmo tempo, modelos geotectônicos evolutivos mais seguros para a região. Entre esses trabalhos mais recentes podese citar os de Barbosa $(1986,1988,1989,1990,1991,1992)$, Barbosa \& Fonteilles (1986, 1989, 1992 no prelo), Wilson (1987), Wilson et al (1988), Xavier et al (1989), Figueiredo (1989), Cruz (1989), Sá \& Barbosa (1991), Conceição et al (1991), Padilha et al (1991), Gomes (1991), Silva (1991), Marinho (1991), Aillon \& Barbosa (1992), Arcanjo et al (1991, 1992), Alibert \& Barbosa (1992), Fornari \& Barbosa

\footnotetext{
* Companhia de Pesquisa e Recursos Minerais, Estrada da Sussuarana, 2862, CEP 00000-000, $6^{\circ}$ Avenida, Centro Administrativo da Bahia, Salvador, Bahia, Brasil

** Curso de Pós-Graduação em Geologia, Instituto de Geociências, Universidade Federal da Bahia, Rua Caetano Moura, 123, CEP 40210-340, Federação, Salvador, Bahia, Brasil
} 
(1992a, 1992b), Figueiredo \& Barbosa (1992 submetido), Barbosa et al. (1992a, 1992b), Marinho et al (1992) e lyer et al. (1995).

No Domínio da Costa Atlântica (Barbosa 1986), apesar do elevado grau de deformação e recristalização das rochas, ainda é possível identificar a natureza original dos granulitos, se magmática ou sedimentar. Assim, de leste para oeste, Barbosa $(1990,1991)$ classificou: (i) granulitos máficos com granada (protólitos semelhantes a basaltos e/ou gabros toleíticos) de arcos insulares; (ii) granulitos intermediários e ácidos (protólitos comparáveis a andesitos basálticos/andesitos e/ou quartzo-dioritos/dacitos/tonalitos, além de riolitos e/ou trondhjemitos) de sequências cálcio-alcalinas do tipo arco de ilha ou margem continental ativa; e (iii) granulitos intermediários com antipertita e mesopertita (protólitos semelhantes a monzonitos-mangeritos e quartzomonzonitos), provavelmente derivados de magma shoshonítico-alcalino, encontrado em arcos de ilhas ou margem continental ativa. Todas essas rochas granulíticas, originalmente vulcânicas e/ou plutônicas, mantêm disposição espacial que permite interpretar a possível existência de um arco insular (Barbosa 1990) ou uma margem continental ativa profundamente erodida (Figueiredo 1989, Figueiredo \& Barbosa 1992). Em ambas possibilidades, as litologias poderiam ter sido o produto da diferenciação de uma suposta placa oceânica, com vergência para oeste. Ainda, segundo Barbosa $(1990,1991)$, este segmento crustal teria sido obductado sobre um proto continente (Domínio JequiéMutuípe-Maracás, Barbosa et al. 1992), situado a oeste do Domínio da Costa Atlântica. A idade de formação desses protólitos seria mais nova que $2.4 \mathrm{Ga}$ (Marinho et al 1992). As principais fases de deformação, bem como o metamorfismo granulítico principal identificado na região foram possivelmente provocados por processos ligados a esta obducção (Barbosa 1990, 1991).

Os elementos geológicos deste trabalho são apresentados de forma simplificada e foram obtidos durante o mapeamento da Folha Itabuna, dentro do Programa Levantamentos Geológicos Básicos (PLGB), executado pelo Convénio DNPM/CPRM (Arcanjo 1991). Vale ressaltar finalmente que neste artigo é tratada somente a geologia das rochas granulíticas, provavelmente de idade proterozóica inferior (Marinho et al 1992), excluindo-se os dados referentes aos diques de diabásios e basaltos de preenchimento de fraturas do Proterózoico Inferior, aos corpos magmáticos anorogênicos, também do Proterózoico Inferior (Suite Intrusiva Itabuna de Lima et al. 1981) do Proterózoico Superior coberturas fanerozóicas do Mesozóico, Terciário e Quaternário.

GEOLOGIA E PETROGRAFIA DAS UNIDADES GEOLÓGICAS A cartografia geológica e a petrografia permitiram separar os terrenos metamórficos de alto grau da região de Itabuna (Fig. 1), em cinco conjuntos de rochas com características próprias, ou sejam: (i) Complexo Ilhéus (CI); (ii) Complexo São José (CSJ); (iii) Complexo Ibicaraí-Buerarema (CIB) e Complexo Rio Japu; além de (iv) Granitóides Rio Paraíso, Água Sumida e São Geraldo (Fig. 2, Tab. 1). Estes Complexos, definidos pelo PLGB/ DNPM/CPRM e mantidos neste trabalho, em geral estão limitados por descontinuidades estruturais profundas representadas por zonas de cisalhamento, em geral associadas às deformações tectônicas dúcteis (Gomes et al 1991, Arcanjo et al 1991, 1992).

Complexo Ilhéus $(\mathbf{C l})$ Encontra-se restrito à parte sudeste da área em foco e exibe poucos afloramentos, já que é praticamente todo recoberto por sedimentos fanerozóicos, a não ser ao longo do litoral, como por exemplo nas proximidades da cidade de Ilhéus (Fig. 2). Nesse local, verifica-se a presença de metamorfitos de textura média a fina, fortemente bandados, com bandas centimétricas a métricas de granulitos intermediários de cor cinza, quartzo-feldspáticos, intercaladas com bandas de granulitos básicos, pretas esverdeadas, ricas em hornblendas e piroxênios. Níveis de granulitos ácidos e corpos pegmatóides, secantes ao bandamento, com textura grossa, de composição tonalítica com hiperstênio, também ocorrem neste complexo de rochas. A mineralogia dessas litologias é exibida na tabela 1.

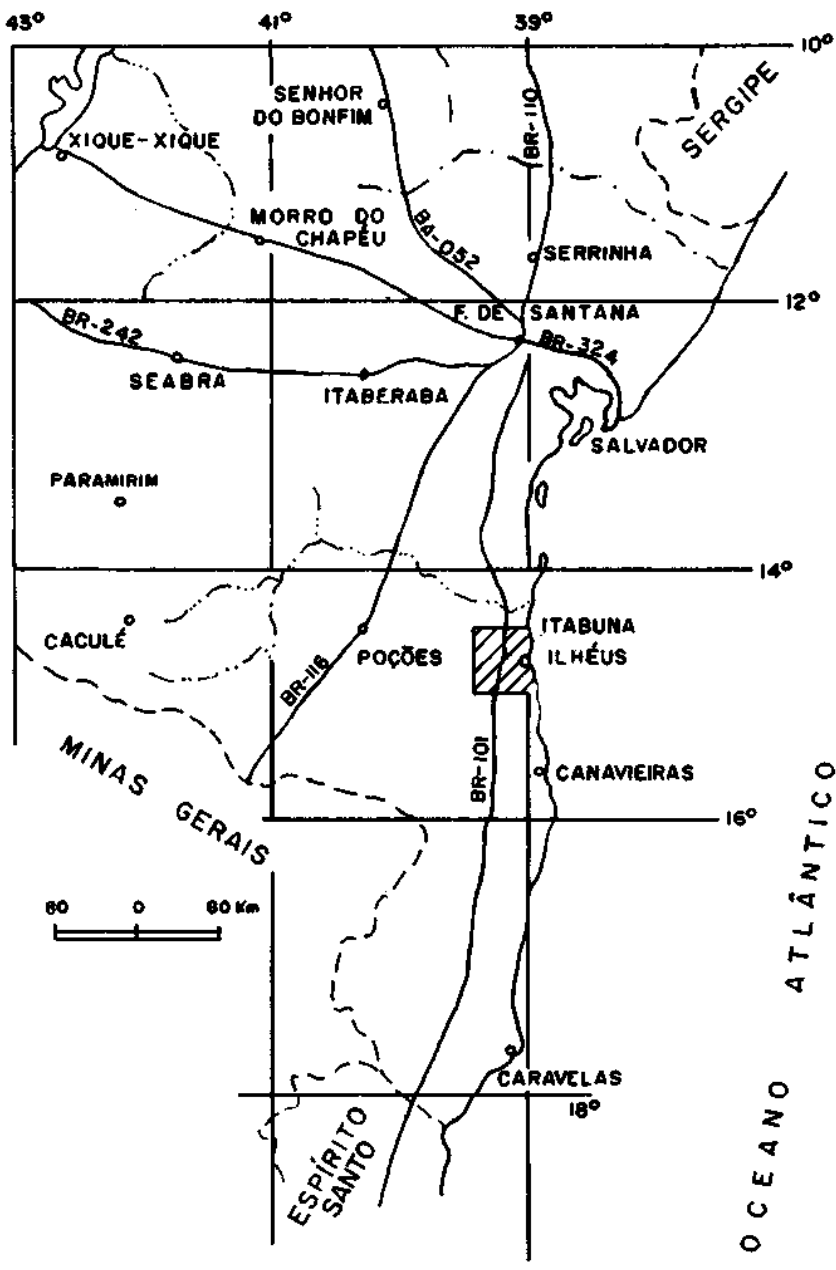

Figura 1 - Localização da área pesquisada em relação ao sul do Estado da Bahia

Figure 1 - Location map of study area with respect to the southern portion of the Bahia State

Complexo São José (CSJ) Ocupa as partes nordeste e central da área, sendo composto de granulitos básicos com granada, básicos e intermediários, estes últimos representando segmento importante do Complexo (Fig. 2, Tab. 1). Todos estes granulitos estão intensamente deformados com uma foliação milonítica, recristalizada, na qual é observada, nos termos intermediários, quartzo estirado, que se salienta nas partes alteradas dos afloramentos. Os granulitos básicos com granada possuem textura fina, são homogéneos, de cor preta e discreto bandamento, assinalado pela presença de grãos de granada, arrumados em níveis que se alternam uns com os outros, formados ora de plagioclásio, ora de plagioclásio mais minerais ferromagnesianos. Os granulitos básicos são também homogêneos, mostrando textura fina a média, por vezes grossa, sendo neste último caso, eventualmente, notadas texturas de cúmulus, semi-preservadas, numa massa recristalizada de cristais metamórficos 
Tabela 1 - Composição mineralógica das rochas granulíticas da região de Itabuna - Bahia

Table 1 - Mineralogical composition of granulitic rocks from the Itabuna region (Bahia)

\begin{tabular}{|c|c|c|c|c|}
\hline Rochas & $\begin{array}{l}\text { Minerais } \\
\text { Relíquias } \\
\text { Plutônicas }\end{array}$ & $\begin{array}{l}\text { Principais Minerais } \\
\text { Metamórficos } \\
\text { (Composição Modal) }\end{array}$ & $\begin{array}{l}\text { Minerais } \\
\text { Acessórios }\end{array}$ & $\begin{array}{c}\text { Minerais } \\
\text { Metamórficos } \\
\text { Retrógrados } \\
\end{array}$ \\
\hline \multicolumn{5}{|l|}{ Complexo Ilhéus (CI) } \\
\hline $\begin{array}{l}\text { Granulitos } \\
\text { intermediários }\end{array}$ & & $\begin{array}{l}\text { Qz (40\%); Mp (20\%); Plag (36\%) } \\
\text { (An 30-50); Opx (2-4\%) }\end{array}$ & Op; Zr; Ap. & $\mathrm{Hb} ; \mathrm{Cl}$ \\
\hline Granulitos básicos & & Plag (58\%) Cpx (21\%); Qz (20\%) & $\begin{array}{l}\mathrm{Gt} ; \mathrm{Escp} \\
\mathrm{Op} ; \mathrm{Zr} ; \mathrm{Ap}\end{array}$ & $\mathrm{Hb} ; \mathrm{Bi} ; \mathrm{Cl}$ \\
\hline \multicolumn{5}{|l|}{$\begin{array}{l}\text { Complexo } \\
\text { São José (CSJ) }\end{array}$} \\
\hline $\begin{array}{l}\text { Granulítos básicos } \\
\text { com granada }\end{array}$ & & $\begin{array}{l}\text { Plag }(50 \%)(\operatorname{An~} 40-50) ; \text { Opx }(15 \%) ; \\
\text { Cpx }(15 \%) ; \text { Gt }(10 \%) ; \mathrm{Qz}(2 \%)\end{array}$ & $\mathrm{Op} ; \mathrm{Zr}$ & $\begin{array}{l}\mathrm{Hb}(5 \%) \\
\mathrm{Bi}(1 \%) ; \mathrm{C} 1\end{array}$ \\
\hline Granulítos básicos & Plag; Opx; Cpx & $\begin{array}{l}\text { Plag }(60 \%)(\text { An } 45-50) ; \text { Opx }(15 \%) \\
\text { Cpx }(20 \%) ; \text { Qz }(5 \%)\end{array}$ & & \\
\hline $\begin{array}{l}\text { Granulitos } \\
\text { intermediários }\end{array}$ & Plag & $\begin{array}{l}\text { Plag }(75 \%)(\text { An } 30-50) ; \mathrm{Qz}(20 \%) \\
\text { Opx (5\%); Cpx(5\%) }\end{array}$ & $\mathrm{Op} ; \mathrm{Zr} ; \mathrm{Ap}$ & $\begin{array}{l}\mathrm{Hb} ; \mathrm{Bi} ; \mathrm{Qz} \\
\mathrm{Op} ; \mathrm{C} 1\end{array}$ \\
\hline \multicolumn{5}{|l|}{$\begin{array}{l}\text { Complexo Ibicarat. } \\
\text { Buerarema (CIB) }\end{array}$} \\
\hline Granulitos básicos & & $\begin{array}{l}\text { Plag (50\%) (An 32); Cpx (20\%); } \\
\mathrm{Hb}(20 \%) ; \mathrm{Opx}(5 \%)\end{array}$ & Op; Ap. & $\mathrm{Bi} ; \mathrm{Hb} ; \mathrm{Gt}$ \\
\hline $\begin{array}{l}\text { Granulitos } \\
\text { intermediários }\end{array}$ & Plag & $\begin{array}{l}\text { Plag (55\%); (An 20-40); Qz }(25 \%) \\
\text { Opx }(7 \%) ; \text { Cpx }(8 \%) ; \operatorname{Mp}(2 \%) \\
\text { Hb }(2 \%)\end{array}$ & $\mathrm{Op} ; \mathrm{Zr} ; \mathrm{Ap}$ & $\mathrm{Hb} ; \mathrm{Bi}$ \\
\hline Granulitos ácidos & & $\begin{array}{l}\text { Plag (70\%) (an 20-40); Qz (25\%); } \\
\mathrm{Mp}(3 \%) ; \mathrm{Opx}(\mathrm{tr}) ; \mathrm{Cpx}(\mathrm{tr})\end{array}$ & $\mathrm{Op} ; \mathrm{Zr} ; \mathrm{Ap}$ & $\mathrm{Hb} ; \mathrm{Bi}$ \\
\hline \multicolumn{5}{|l|}{ Complexo Rio Japu } \\
\hline Hormblenda Gnaisses & & $\begin{array}{l}\text { Plag }(35 \%) ; \mathrm{Hb}(15 \%) ; \mathrm{Qz}(28 \%) \\
\mathrm{Bi}(10 \%) ; \mathrm{Mic}(5 \%) ; \mathrm{Gt}(2 \%)\end{array}$ & $\mathrm{Op}$ & $\mathrm{Bi} ; \mathrm{Hb} ; \mathrm{Cl}$ \\
\hline Biotita Gnáisses & & $\begin{array}{l}\text { Plag }(50 \%) ; \mathrm{Qz}(30 \%) ; \mathrm{Bi}(13 \%) \\
\mathrm{Hb}(5 \%) ; \mathrm{Gt}(2 \%)\end{array}$ & Op & $\mathrm{Bi} ; \mathrm{Hb} ; \mathrm{C} 1$ \\
\hline \multicolumn{5}{|l|}{$\begin{array}{l}\text { Granitoide Água } \\
\text { Sumida (AS) }\end{array}$} \\
\hline $\begin{array}{l}\text { Monzodioritos, } \\
\text { monzonitos e sienitos } \\
\text { Granitóide Rio } \\
\text { Paraíso (RP) }\end{array}$ & $\begin{array}{l}\mathrm{Mp}(50 \%) ; O p x \\
(3 \%) ; \mathrm{Cpx}(4 \%)\end{array}$ & $\begin{array}{l}\text { Mp (5\%); Opx (15\%); Cpx (12\%); } \\
\text { Plag antp (7\%); Qz (4\%); Hb (1\%) }\end{array}$ & $\mathrm{Op} ; \mathrm{Zr} ; \mathrm{Ap}$ & $\mathrm{Bi} ; \mathrm{Hb} ; \mathrm{Mic}$ \\
\hline $\begin{array}{l}\text { Monzodioritos, } \\
\text { monzonitos e sienitos }\end{array}$ & $\begin{array}{l}\text { Qz }(32 \%) \\
\text { Plag antp (30\%); } \\
\text { Opx (4\%) } \\
\text { Cpx (4\%) }\end{array}$ & Plag (10\%); (An 30-50); Qz (20\%) & Op; Zr; Ap. & $\mathrm{Bi} ; \mathrm{Hb} ; \mathrm{Mic}$ \\
\hline \multicolumn{5}{|l|}{$\begin{array}{l}\text { Granitóide São } \\
\text { Geraldo (SG) }\end{array}$} \\
\hline $\begin{array}{l}\text { Granitos, monzo- } \\
\text { dioritos, monzonitos }\end{array}$ & $\begin{array}{l}\text { Qz }(40 \%) ; \mathrm{Mp} \\
(10 \%) ; \text { Plag } \\
\text { antp (17\%) }\end{array}$ & Mp $(23 \%) ;$ Plag antp (10\%) & $\mathrm{Op} ; \mathrm{Zr} ; \mathrm{Ap}$ & $\mathrm{Bi} ; \mathrm{Hb} ; \mathrm{Mic}$ \\
\hline
\end{tabular}

Abreviações: Opx - ortopiroxênios; Cpx - clinopiroxênios; Plag - plagioclásios; Antp - antipertíticos; Bi - biotitas; Mp - mesopertita; Qz - quartzo; Gt granada; Zr - zircão; Op - opacos; Ap - apatita; Cl - clorita; Mie - mica; Hb - hornblenda; Escp - Escapolita 


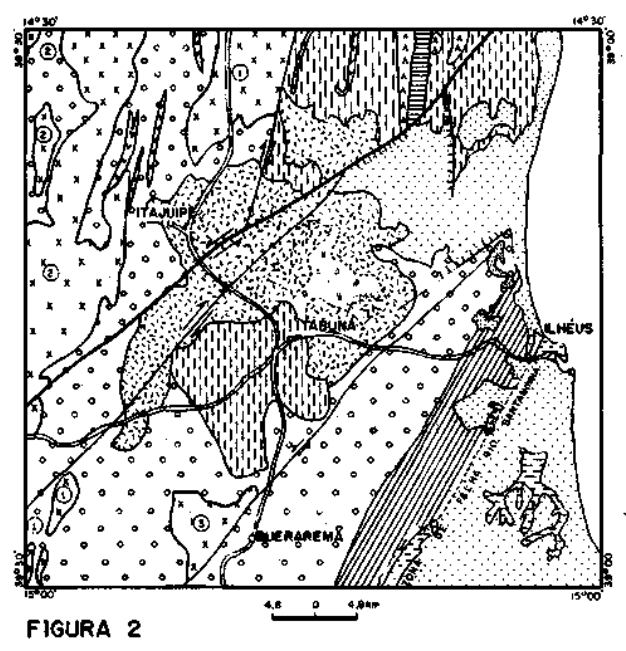

W COEERTURAS FAMEROZZÓICAS

SUITE INTRUSIVA ITAEUNA E GABROS (PROTEROZOHCO SUPERIOR)

[G] SUITE INTRUSINI ITAEUNA E GABROS (PFOTEROZOHCO SUPERIOR)

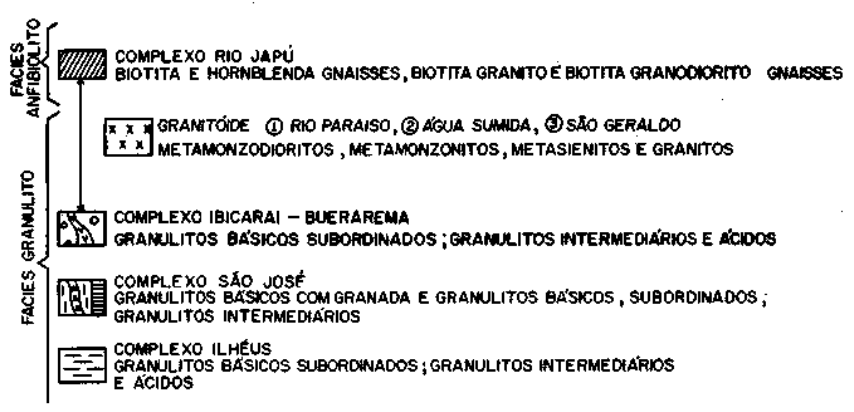

Figura 2 -Mapa geológico simplificado da área pesquisada Figure 2 - Simplified geologic map of the study area

(Arcanjo et al. 1991). Ambos os tipos de granulitos básicos são encontrados em afloramentos, sob a forma de corpos decimétricos, estirados, dispostos linearmente na direção $\mathrm{N}-\mathrm{S}$, envolvidos por uma encaixante composta de granulitos intermediários. Estes últimos são rochas de coloração cinza esverdeada, granulação média, com estrutura bandada, gnáissica, materializada na presença de níveis mais ácidos, intercalados com níveis mais intermediários. Exibem em lâmina delgada, textura equi a inequigranular, onde o quartzo e o plagioclásio são os minerais predominantes, embora ocorram alguns máficos como piroxênios, opacos e hornblendas. $\mathrm{Na}$ tabela 1, são mostradas as paragêneses primárias e secundárias desses três tipos de granulitos que constituem o denominado Complexo São José (Arcanjo et al. 1991).

Complexo Ibicaraí-Buerarema (CIB) e Complexo Rio Japu Ocupam partes dos setores ocidental, sul e centro-oeste da área em estudo (Fig. 2).

O Complexo Ibicaraí-Buerarema é constituído de granulitos básicos e, sobretudo, de granulitos intermediários e ácidos. Os granulitos básicos, de cor preta-esverdeada, são compostos basicamente de plagioclásios e piroxênios, representando corpos isolados, lenticulares, dispostos paralelamente ao trend regional $\mathrm{N}-\mathrm{S}$ da área e inclusos nos granulitos intermediários e ácidos (Arcanjo et al. 1991, 1992). Os granulitos intermediários e ácidos, formados de plagioclásio, quartzo e escassos piroxênios, são fortemente deformados, possuindo ora discreto, ora proeminente bandamento gnáissico, traduzido pela alternância de níveis mais ácidos (centimétricos) e níveis intermediários (métricos). São de cor cinza, em geral de granulação média, com destaque para esporádicos níveis grossos, contendo quartzo e plagioclásio, estirados. Detalhes da mineralogia desses granulitos intermediários e ácidos são mostrados na tabela 2. Nesta, é feita referência aos minerais plutônicos reliquiares, minerais formados no clímax do metamorfismo e minerais metamórficos retrógrados.

Os granulitos básicos e intermediários, do denominado Complexo Ibicaraí-Buerarema, são semelhantes àqueles básicos e intermediários do Complexo São José descritos anteriormente, embora, nos granulitos intermediários do primeiro, tenham sido encontrados traços de mesopertita, inexistentes no segundo. Estes, por sua vez, encerram mais corpos de granulitos básicos que o Complexo IbicaraíBuerarema.

As rochas do Complexo Rio Japu, segundo Arcanjo et al. (1991), são representadas por hornblenda-biotita gnaisses, sendo comparáveis às rochas do Complexo Ibicaraí-Buerarema. A principal diferença, segundo esses autores, é que as rochas do Complexo Rio Japu foram reequilibradas na fácies anfibolito, em níveis crustais menos profundos que aqueles do Complexo Ibicaraí-Buerarema, este reconhecidamente da fácies granulito. A concorrência de fácies anfibolitos/granulitos justapostas provavelmente deve-se às fatias de cavalgamento com níveis crustais algo diferentes, sendo colocados lado-a-lado. Na tabela 1, pode ser verificada a mineralogia dessas litologias, tanto as paragêneses metamórficas primárias, equilibradas no pico do metamorfismo, quanto aquelas acessórias e secundárias, formadas durante o retrometamorfismo que atingiu a área (Arcanjo et al. 1991, 1992).

Granitóides Água Sumida (AS), Rio Paraíso (RP) e São Geraldo (SG) Os principais granitóides da área, denominados de Água Sumida, Rio Paraíso e São Geraldo, foram reequilibrados na fácies granulito, são deformados e apresentam maiores dimensões na direção meridiana (Fig. 2). O corpo de Agua Sumida pode ser classificado, segundo Streckeisen (1976), como constituído de monzodioritos, monzonitos e sienitos, homogêneos, de cor cinza-esverdeada, textura média a grossa, sendo foliados verticalmente. $\mathrm{O}$ corpo Rio Paraiso constitui-se quase exclusivamente de monzonitos, com grande uniformidade textural, interrompida apenas por delgadas bandas enriquecidas em minerais máficos, as quais são paralelas à foliação da rocha; apresenta textura dominantemente granoblástica, com fenocristais de quartzo, plagioclásio antipertítico e piroxênio, imersos numa matriz recristalizada de plagioclásio mais quartzo. $\mathrm{O}$ corpo denominado de São Geraldo, é composto de rochas com textura granoblástica e com composição mineralógica predominanternente granítica. A mineralogia desses granitóides, não só a metamórfica como também a plutônica, às vezes parcialmente preservada, das deformações e da granulitização, é mostrada em detalhe na tabela 1.

\section{PETROQUÍMICA DAS UNIDADES GEOLÓGICAS}

As amostras de rocha pesaram em torno de $15 \mathrm{~kg}$ cada, tendo sido britadas e moídas abaixo de $150 \mathrm{mash}$, na Superintendência Regional de Salvador da CPRM, após o controle petrográfico e do grau de alteração provocado por qualquer agente. Elas foram analisadas para os óxidos maiores, umidade e perda ao fogo no Laboratório Central de Análises Minerais da CPRM - LAMIN e da Paulo Abib Engenharia; para os elementos traços $\mathrm{Sr}, \mathrm{Rb}, \mathrm{Zr}, \mathrm{Nb}$ e Y por fluorescência de Raios-X e, para $\mathrm{Cu}, \mathrm{Pb}, \mathrm{Zn}, \mathrm{Co}, \mathrm{Cr}$, Ni, V e B, por Espectrometria de absorção atômica, abertura total, em ambos os casos no LAMIN. Finalmente, para os elementos Terras Raras por espectrometria de plasma na GEOSOL Geologia e Sondagens Ltda. 
O estudo petroquímico das rochas granulíticas da região sudeste da Bahia, utilizando elementos químicos maiores, traços e Terras Raras, sobretudo aqueles considerados poucos móveis ou inertes diante dos processos metamórficos, tem possibilitado estimar as características dos protólitos pré-granulitização e, conseqüentemente, em muitos casos, tecer considerações, não só sobre os tipos de magmas que os geraram, mas, também, sobre o grau de evolução da sua diferenciação. Ademais, com a identificação dos protólitos, tem sido possível classificar melhor as rochas granulíticas, cartografá-las segundo sua natureza original e estabelecer modelos geotectônicos mais coerentes visando explicar a evolução de parte da crosta continental inferior, onde são encontradas essas rochas de alto grau.

$\mathrm{Na}$ região de Itabuna, foram realizadas diversas determinações químicas (Arcanjo et al. 1991, Tab. 2) cujo estudo trouxe bons resultados para entender melhor sua geologia, como será demonstrado no decorrer deste trabalho. A seguir são descritas, de forma resumida, as características químicas desses granulitos, seguindo a mesma subdivisão utilizada nos itens e sub-itens anteriores.

\section{Complexo Ilhéus (Cl)}

Os granulitos que constituem esse Complexo (Fig. 2) possuem, na sua maioria rochas intermediárias, com teores de $\mathrm{SiO}_{2}$ variando de 53 a $62 \%$ (Tab. 2). Esses valores usados em relação ao potássio, como exemplificado no gráfico de Peccerillo \& Taylor (1976) (Fig. 3), mostram que os pontos correspondentes a análises químicas das rochas desse Complexo se distribuem relativamente bem no campo dos basaltos andesíticos/dioritos e, sobretudo, no campo dos andesítos/quartzo-dioritos filiados a séries cálcio-alcalinas de alto potássio de arcos de ilhas maduros ou margem continental ativa. Essa filiação também é confirmada se utilizado o diagrama binário de Tegyey (1979), que considera relações matemáticas de proporções moleculares de $\mathrm{K}_{2} \mathrm{O}, \mathrm{Na}_{2} \mathrm{O}$ - na abcissa - e $\mathrm{MgO}$, FeO e $\mathrm{MnO}$ - na ordenada (Fig. 4). O caráter cálcio-alcalino é ainda ratificado pelas concentrações médias dos elementos maiores $\mathrm{SiO}_{2}, \mathrm{TiO}_{2}, \mathrm{Al}_{2} \mathrm{O}_{3}, \mathrm{CaO}, \mathrm{Na}_{2} \mathrm{O}$ e $\mathrm{K}_{2} \mathrm{O}$, dos elementos traços $\mathrm{Rb}, \mathrm{Ba}, \mathrm{Pb}, \mathrm{Sr}$, La e $\mathrm{Cr}$, além das razões de concentra-

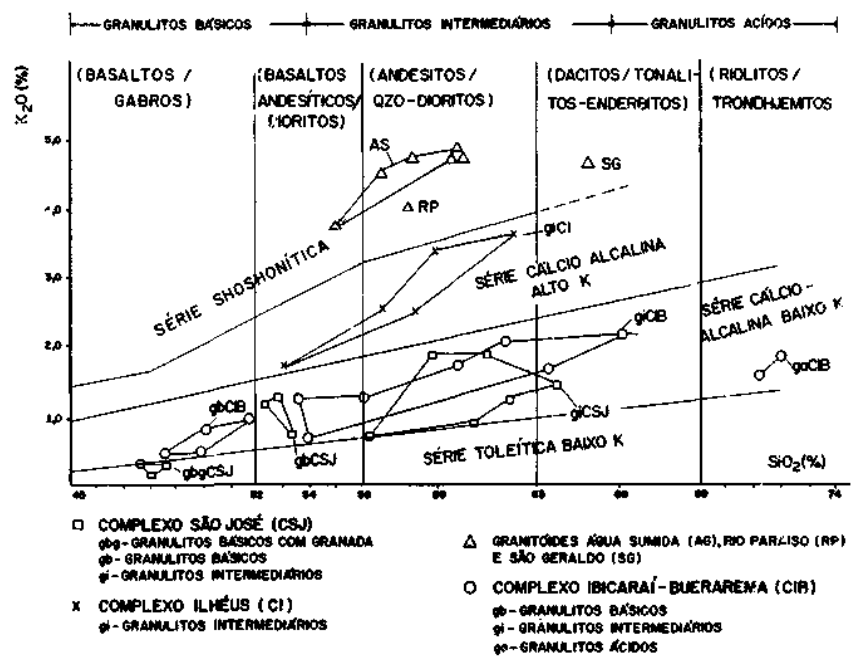

Figura 3 - Distribuição das unidades litológicas da área pesquisada no diagrama de Peccerillo \& Taylor (1976), que caracteriza rochas toleiticas, cálcio-alcalinas e shoshoniticas de arcos-de-ilhas ou margens continentais ativas Figure 3 - Plot of the lithologic units of the study area on the Peccerillo \& Taylor (1976) diagram. This diagram is used to characterize tholeiitic, calc-alkaline, and shoshonitic rocks formed at island ares or active continental margins

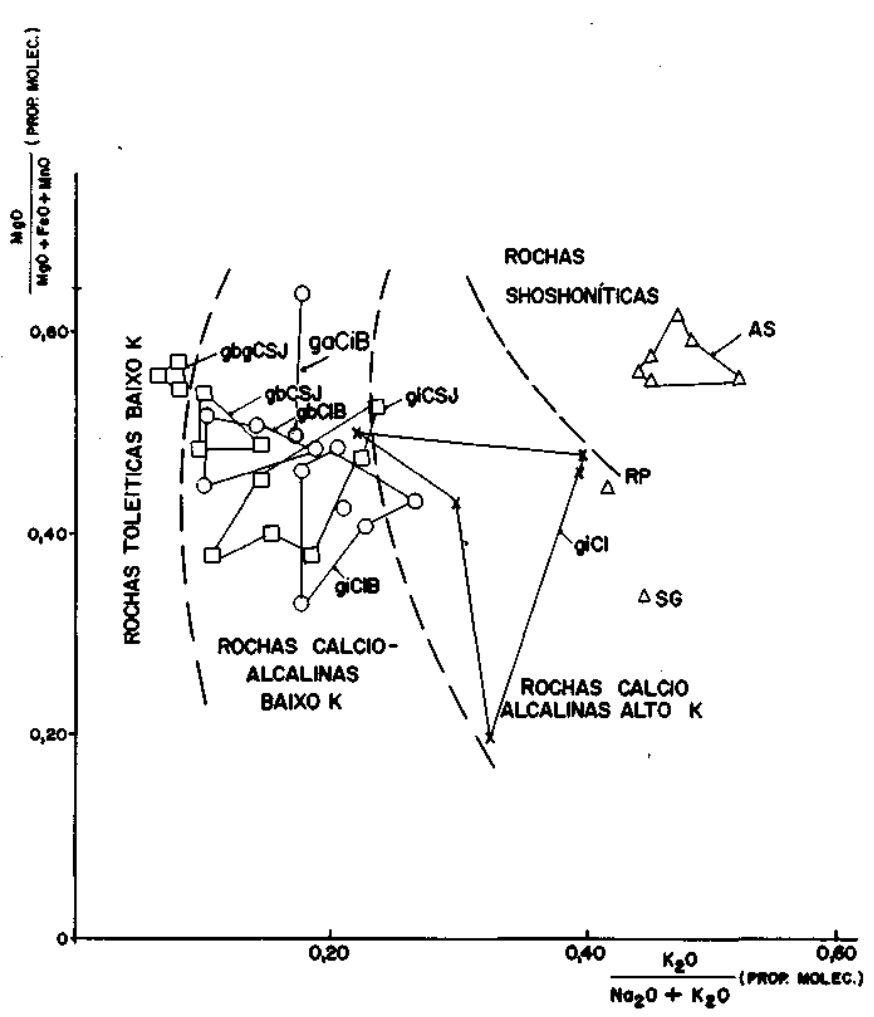

Figura 4 - Localização das unidades litológicas da área pesquisada no diagrama de Tegyey (1979). Observar a distribuição dos granulitos nos quatro campos que caracterizam rochas de arcos-de-ilhas ou margens continentais ativas. Mesma simbologia da figura 3

Figure 4 - Plot of the lithologic units of the study area on the Tegyey (1979) diagram. Note that the granulites plot on the four fields that characterize rocks formed at island ares or active continental margins. Same simbology of figure 3

coes $\mathrm{K} / \mathrm{Rb}, \mathrm{Rb} / \mathrm{Sr}$ e $\mathrm{La} / \mathrm{Yb}$ (Tab. 2). Além disso, como demonstrado na figura 5 , os granulitos intermediários do Complexo Ilhéus são de caráter metaluminoso. São rochas relativamente ricas em plagioclásio (Tab. 1 ), com teores de $\mathrm{CaO}$ variando de cerca de 7 até $5 \%$ e $\mathrm{Na}_{2} \mathrm{O}$ quase constante em torno de 3,5\% (Fig. 6). Os teores de ferro total - oscilando de 10,80 até $7,82 \%$ - são compatíveis com a quantidade de opacos e ortopiroxênio. Esta última fase mineral absorveu todo o magnésio contido na rocha original, o qual varia entre 3,9 e $2,6 \%$ (Fig. 7). $\mathrm{O} \mathrm{TiO}_{2}$, elemento incompatível na cristalização do material magmático que deu origem aos granulitos intermediários em foco, varia pouco, com diferença de aproximadamente $0,20 \%$ nos termos intermediários, tendo se concentrado especialmente nos minerais opacos (Tab. 2, Fig. 8). São rochas relativamente ricas em $\mathrm{Sr}$, como mostrado na tabela 2 e figura 9.

Com relação aos elementos Terras Raras, o padrão médio dos granulitos intermediários desse Complexo se coaduna com aquele considerado como cálcio-alcalino de alto potássio. Na tabela 2 e figura 10, essa assertiva pode ser verificada, já que estas rochas mostram relativamente altos conteúdos em Terras Raras leves, situando-se entre 100 e 200 vezes o condrito (Masuda et al. 1973), sendo fracamente empobrecidos em Terras Raras pesadas.

Complexo São José (CSJ) O diagrama de Peccerillo \& Taylor (1976) (Fig. 3) demonstra que essas rochas gra-nulíticas são diferentes das do Complexo Ilhéus, descritas anteriormente. Ainda nesta figura, nota-se que os pontos representativos das análises químicas dos granulitos bási- 


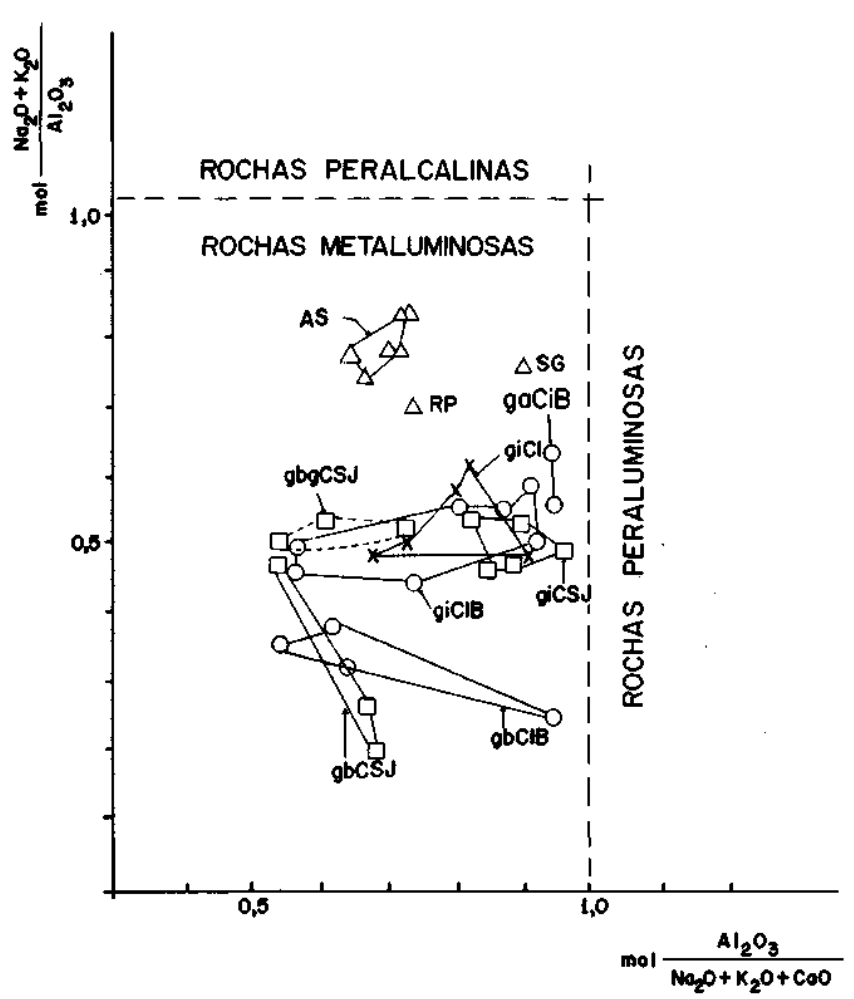

Figura 5 - Distribuição das litologias da área em foco no diagrama de Rapela \& Caminos (1987). Observar que todas se situam no campo das rochas metaluminosas. Mesma símbologia da figura 3

Figure 5 - Plot of the lithologic units of the study area on the Rapela \& Caminos (1987) diagram. Note that ali lithologies plot on the field of the metaluminous rocks. Same simbology of figure 3

cos do Complexo São José situam-se no campo dos basaltos andesíticos/dioritos e, aqueles representativos dos granulitos intermediários, dispõem-se no campo dos andesitos/ quartzo-dioritos, todos distribuindo-se no domínio da série cálcio-alcalina de baixo potássio, de arco-de-ilha ou margem continental ativa. Constatação da filiação cálcio-alcalina de baixo potássio, também pode ser feita na figura 4. Por sua vez, na figura 5, a qual foi estabelecida por Rapela \& Caminos (1987), fica claro o caráter metaluminoso dessas rochas. Ainda com relação aos granulitos básicos deste Complexo, os diagramas das figuras 11 (Pearce 1976), 12 (Pearce \& Cann 1973) e 13 (Pearce 1975) mostram que seus protólitos foram provavelmente basaltos andesíticos/dioritos, cálcio-alcalinos de arco-de-ilha. Esses granulitos básicos são portadores, em geral, de $35 \%$ de piroxênios, $60 \%$ de plagioclásios e praticamente desprovidos de quartzo (Tab. 1). Estas constatações são reflexo da composição química dessas rochas, exemplificadas nas figuras 6, 7, 8 e 9. Nessas figuras, embora verifique-se certa dispersão dos pontos representativos dos granulitos básicos e intermediários, eles se alinham grosseiramente sobre trenas. Estes são reflexos de provável cogeneticidade dessas rochas. Com relação aos elementos Terras Raras, a figura 10 demonstra que o padrão do granulito intermediário da amostra JB-330A, tomada como exemplo do Complexo São José (Tab. 2), é semelhante àquele de andesitos/dioritos cálcio-alcalinos de arcos de ilhas (Morrison 1980). Ainda na figura 10, fica patente o acentuado fracionamento dos elementos Terras Raras, com forte inclinação da curva de distribuição e anomalia negativa de európio. Estes fatos, aliados aos elevados teores de $\mathrm{Al}_{2} \mathrm{O}_{3}$ (Tab. 2), sugere fonte máfica para estes

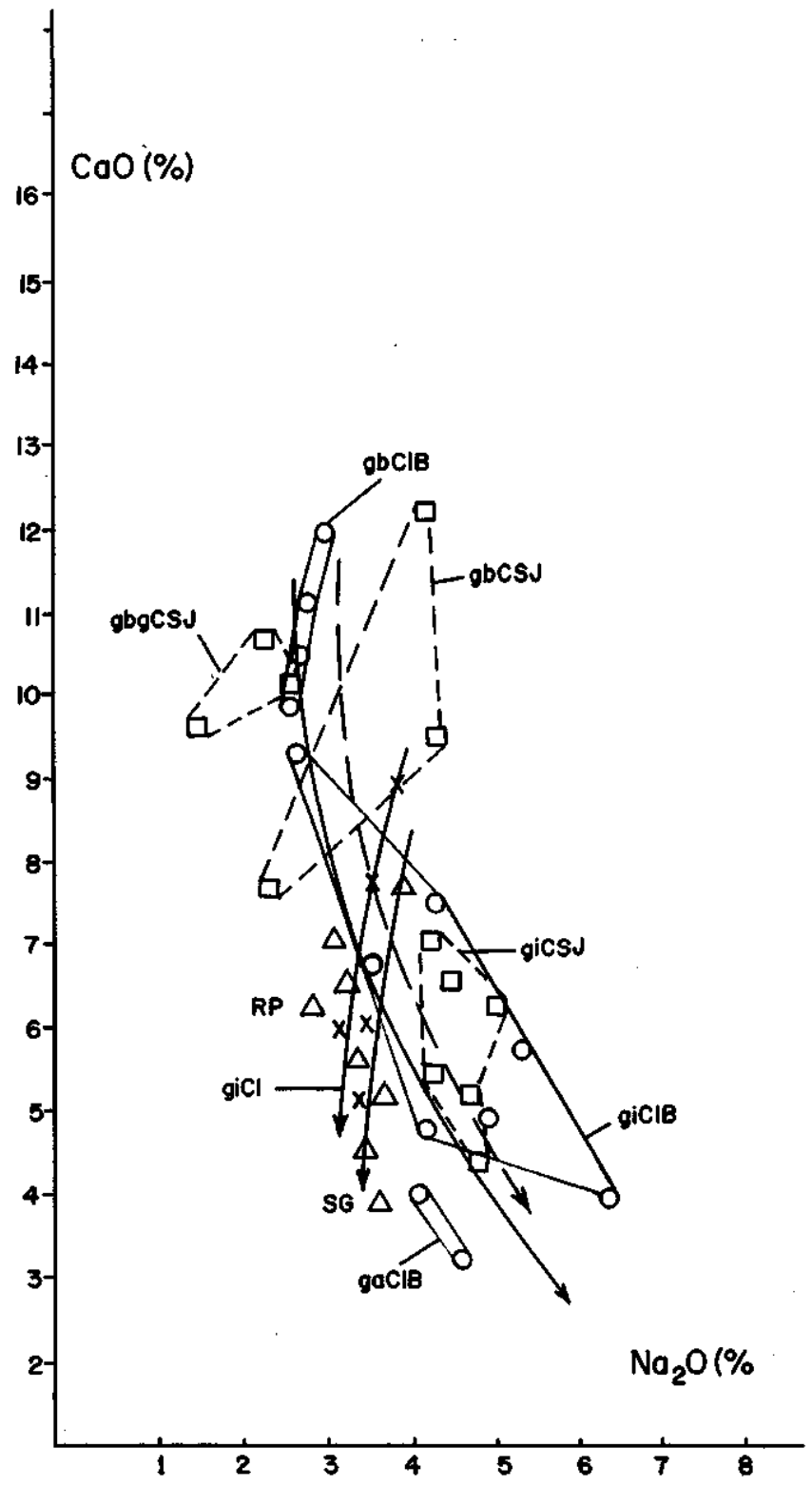

Figura 6- Litologias da área de estudo no diagrama binário $\mathrm{CaO} \times \mathrm{Na}_{2} \mathrm{O}$. Observar que apesar de uma certa dispersão dos pontos, as litologias se situam em trends diferentes entre si. Mesma simbologia da figura 3

Figure 6 - Plot of the lithologic units of the study area on the $\mathrm{CaOxNa}_{2} \mathrm{O}$ binary diagram. Note that despite the dispersion on the points, the lithologies group in different trends. Same simbology of figure 3

granulitos intermediários, com abundante piroxênio e plagioclásio, em ambiente geotectônico do tipo margem continental (Yang 1985).

Como referido anteriormente, também no Complexo São José, ocorrem granulitos básicos portadores de granada. Estes são encontrados sob a forma de corpos decimétricos, estirados na direção N-S, envolvidos por uma encaixante composta pelos granulitos intermediários descritos antes. Nas figuras 3, 4 e 11, verifica-se que esses granulitos básicos podem ser interpretados como basaltos/gabros, de filiação toleítica de baixo potássio, diferentemente dos outros granulitos básicos deste complexo, não-portadores de granada, que foram considerados como os membros mais básicos de uma sequência cálcio-alcalina de baixo potássio, tipo arco de ilha (Barbosa 1990) ou margem continental ativa (Figueiredo 1989, Figueiredo \& Barbosa 1992). Os 
Tabela 2 - Análises químicas de elementos maiores, traços e Terras Raras de mochas granulíticas da regiäo de ltabuna - Bahia Table 2 - Chemical analysis of major, trace and Rare Earth elements of granulitic rocks of the Itabuna region (Bahia)

\begin{tabular}{|c|c|c|c|c|c|c|c|c|c|c|c|c|c|c|c|c|c|}
\hline \multirow{2}{*}{$\begin{array}{l}\text { Amostras/ } \\
\text { Elementos }\end{array}$} & \multicolumn{5}{|c|}{ Complexo Ilhéus (CI) } & \multicolumn{12}{|c|}{ Complexo São José ( CSJ) } \\
\hline & $\begin{array}{r}\text { JB- } \\
59 \\
\end{array}$ & $\begin{array}{c}\text { JB- } \\
58 \\
\end{array}$ & $\begin{array}{l}\text { JB- } \\
262 \\
\end{array}$ & $\begin{array}{c}\text { JB- } \\
302 F\end{array}$ & $\begin{array}{c}\text { JB- } \\
\text { 302A }\end{array}$ & $\begin{array}{c}\text { JB- } \\
26 \\
\end{array}$ & $\begin{array}{c}\text { JB- } \\
218 B\end{array}$ & $\begin{array}{l}\text { JB- } \\
225 \\
\end{array}$ & $\begin{array}{c}\text { JB- } \\
286 A\end{array}$ & $\begin{array}{l}\text { JB- } \\
223 \\
\end{array}$ & $\begin{array}{r}\text { JB- } \\
\text { 308A } \\
\end{array}$ & $\begin{array}{l}\text { JB- } \\
256 \\
\end{array}$ & $\begin{array}{l}\text { JB- } \\
31 \mathrm{~A}\end{array}$ & $\begin{array}{c}\text { JB- } \\
\text { 330A }\end{array}$ & $\begin{array}{l}\text { JB- } \\
189 \\
\end{array}$ & $\begin{array}{l}\text { JB- } \\
222 \\
\end{array}$ & $\begin{array}{r}\text { JB- } \\
34 \mathrm{~A} \\
\end{array}$ \\
\hline $\mathrm{SiO}_{2} \%$ & 53,10 & 56,90 & 58,10 & 58,90 & 62,00 & 47,50 & 47,60 & 48,60 & 52,40 & 53,50 & 54,90 & 56,30 & 59,00 & 60,50 & 61,00 & 61,90 & 63,80 \\
\hline $\mathrm{Al}_{2} \mathrm{O}_{3} \%$ & 16,20 & 16,60 & 17,00 & 15,10 & 15,00 & 14,20 & 16,10 & 16,10 & 16,40 & 15,20 & 17,20 & 18,00 & 16,10 & 16,10 & 16,10 & 16,10 & 17,00 \\
\hline $\mathrm{Fe}_{2} \mathrm{O}_{3} \%$ & 7,24 & 5,95 & 3,60 & 3,80 & 5,20 & 6,00 & 4,50 & 3,90 & 3,53 & 5,07 & 4,76 & 2,60 & 1,70 & 2,40 & 1,10 & 3,30 & 1,30 \\
\hline $\mathrm{FeO} \%$ & 4,42 & 3,87 & 4,50 & 4,30 & 2,62 & 11,30 & 8,90 & 8,60 & 4,63 & 6,21 & 5,04 & 5,20 & 5,20 & 5,00 & 5,00 & 2,70 & 3,70 \\
\hline $\mathrm{MnO} \%$ & 0,14 & 0,10 & 0,12 & 0,13 & 0,09 & 0,24 & 0,19 & 0,17 & 0,11 & 0,13 & 0,11 & 0,10 & 0,09 & 0,10 & 0,08 & 0,08 & 0,08 \\
\hline $\mathrm{MgO} \%$ & 4,26 & 2,85 & 2,80 & 3,30 & 2,60 & 5,90 & 7,30 & 7,40 & 2,41 & 4,66 & 3,67 & 4,60 & 3,70 & 2,30 & 2,80 & 2,30 & 1,50 \\
\hline $\mathrm{CaO} \%$ & 8,91 & 7,68 & 5,90 & 5,90 & 5,05 & 9,70 & 10,20 & 10,80 & 12,30 & 9,61 & 8,53 & 7,00 & 5,90 & 6,40 & 5,30 & 6,10 & 5,00 \\
\hline $\mathrm{Na}_{2} \mathrm{O} \%$ & 3,71 & 3,57 & 3,50 & 3,20 & 3,41 & 1,60 & 2,80 & 2,40 & 4,24 & 4,29 & 4,12 & 4,00 & 4,00 & 4,10 & 4,10 & 4,60 & 4,30 \\
\hline $\mathrm{K}_{2} \mathrm{O} \%$ & 1,62 & 2,41 & 2,40 & 3,30 & 3,52 & 0,18 & 0,34 & 0,31 & 1,13 & 0,72 & 1,27 & 0,60 & 1,80 & 0,73 & 1,80 & 1,20 & 1,40 \\
\hline $\mathrm{TiO}_{2} \%$ & 1,06 & 0,97 & 0,73 & 0,83 & 0,72 & 1,80 & 1,50 & 1,50 & 0.85 & 1,49 & 2,29 & 0,42 & 1,00 & 1,10 & 0,94 & 0,62 & 0,94 \\
\hline $\mathrm{P}_{2} \mathrm{O}_{5} \%$ & 0,40 & 0,35 & 0,39 & 0,41 & 0,11 & 0,40 & 0,19 & 0,21 & 1,24 & 0,15 & 0,90 & 0,12 & 0,24 & 0,38 & 0,33 & 0,32 & 0,31 \\
\hline $\mathrm{H}_{2} \mathrm{O} \%$ & . & 0,00 & 0,30 & 0,30 & 0,11 & 0,30 & 0,20 & 0,10 & 0,60 & 0,00 & 0,08 & 0,60 & 0,20 & 0,40 & 0,50 & 0,10 & 0,10 \\
\hline P.F. & - & - & 0,50 & 0,40 & 0,11 & 0,90 & 0,20 & 0,10 & 1,02 & 0,12 & 0,45 & 1,00 & 0,60 & 0,40 & 0,70 & 0,40 & 0,50 \\
\hline TOTAL & 101,06 & 101,25 & 99,84 & 99,87 & 100,54 & 100,02 & 100,02 & 99,99 & 100,32 & 101,15 & 103,32 & 100,54 & 99,53 & 99,91 & 99,75 & 99,72 & 99,93 \\
\hline Cu ppm & 70,00 & 40,00 & 46,00 & 43,00 & 18,00 & 156,00 & 90,00 & 112,00 & 165,00 & 30,00 & 25,00 & 28,00 & 9,00 & 20,00 & 30,00 & 74,00 & 23,00 \\
\hline $\mathrm{Pb}$ ppm & 20,00 & 30,00 & 4,00 & 10,00 & 6,00 & 4,00 & 8,00 & 4,00 & 30,00 & 20,0 & 20,00 & 4,00 & 24,00 & 12,00 & 4,00 & 22,00 & 4,00 \\
\hline Zn ppm & 100,00 & 95,00 & 22,00 & 50,00 & 30,00 & 24,00 & 33,00 & 18,00 & 90,00 & 90,00 & 90,00 & 21,00 & 55,00 & 23,00 & 21,00 & 25,00 & 15,00 \\
\hline Co ppm & 30,00 & 30,00 & 11,00 & 11,00 & 7,00 & 27,00 & 25,00 & 19,00 & 25,00 & 40,00 & 25,00 & 16,00 & 12,00 & 9,00 & 9,00 & 15,00 & 6,00 \\
\hline Cr ppm & 100,00 & 50,0 & 30,00 & 55,00 & 40,00 & 60,00 & 205,00 & 225,00 & 50,00 & 125,00 & 75,00 & 70,00 & 25,00 & 70,00 & 55,00 & 130,00 & 15,00 \\
\hline Ni ppm & 10,00 & 10,00 & 18,00 & 9,00 & 6,00 & 61,00 & 100,00 & 124,00 & 35,00 & 45,00 & 30,00 & 57,00 & 15,00 & 25,00 & 29,00 & 76,00 & 5,00 \\
\hline$V \mathrm{ppm}$ & 160,00 & 160,00 & 110,00 & 76,00 & 160,00 & 270,00 & 230,00 & 230,00 & 100,00 & 200,00 & 120,00 & 80,00 & 160,00 & 44,00 & 90,00 & 36,00 & 50,00 \\
\hline Ba ppm & 3.200 & 3.850 & 1.600 & - & 1.140 & 5,00 & 75,00 & 75,00 & 3.750 & 1.300 & 4.450 & 325,00 & 960,00 & - & 850,00 & 1.600 & 1.150 \\
\hline Sr ppm & 631,00 & 696,00 & 709,00 & 488,00 & 409,00 & 735,00 & 82,00 & 90,00 & 1.000 & 311,00 & 794,00 & 80,00 & 428,00 & 413,00 & 618,00 & 1000 & 394,00 \\
\hline Rb ppm & 10,00 & 10,0 & 26,00 & 95,00 & 105,00 & 155,00 & 10,00 & 10,0 & 10,00 & 10,0 & 10,00 & 60,00 & 141,00 & 10,00 & 42,00 & 10,0 & 10,0 \\
\hline $\mathrm{Zr} \mathrm{ppm}$ & 71,00 & 73,00 & 13,00 & 101,00 & 189,00 & 115,00 & 72,00 & 61,00 & 260,00 & 123,00 & 349,00 & 661,00 & 162,00 & 299,00 & 178,00 & 50,00 & 40,00 \\
\hline $\mathrm{Nb}$ ppm & 10,00 & 10,0 & 10,00 & 10,00 & 10,00 & 10,0 & 10,00 & 10,0 & 10,00 & 10,0 & 10,00 & 10,0 & 10,00 & 10,00 & 10,0 & 10,0 & 10,0 \\
\hline Y ppm & 19,00 & 26,00 & 11,00 & 18,00 & 21,00 & 10,0 & 26,00 & 20,00 & 316,00 & 36,00 & 41,00 & 20,00 & 10,00 & 24,00 & 18,00 & 10,0 & 29,00 \\
\hline Ti ppm & - & . & - & - & - & 10789 & 8991 & 8991 & 5095 & 8931 & 13726 & - & - & - & - & - & - \\
\hline La ppm & - & - & - & 39,58 & - & 5,31 & 6,13 & - & - & - & - & - & . & 36,94 & 181,90 & - & - \\
\hline Ce ppm & - & - & - & 97,81 & - & 13,60 & 12,60 & - & - & - & - & $=$ & $=$ & 78,89 & 331,20 & $=$ & - \\
\hline Nd ppm & - & - & - & 47,64 & - & 13,26 & 12,05 & - & - & - & - & - & - & 34,90 & 166,20 & - & - \\
\hline Sm ppm & - & - & - & 8,41 & - & 4,19 & 2,90 & - & - & - & - & - & - & 6,20 & 25,96 & - & - \\
\hline Eu ppm & - & - & - & 1,59 & - & 1,16 & 0,89 & - & - & - & - & - & $=$ & 1,45 & 5,25 & - & - \\
\hline Gd ppm & - & - & - & 5,67 & - & 5,07 & 3,24 & - & - & - & . & - & - & 4,96 & 15,36 & - & - \\
\hline Dy ppm & - & - & . & 5,18 & . & 5,54 & 4,05 & . & - & - & - & - & - & 4,57 & 7,01 & - & - \\
\hline Er ppm & - & $=$ & - & 2,86 & - & 3,79 & 3,09 & $=$ & - & . & - & - & - & 2,59 & 3,15 & - & - \\
\hline Yb ppm & - & - & - & 2,52 & - & 3,47 & 2,80 & - & - & - & - & - & - & 2,23 & 1,80 & - & - \\
\hline Lu ppm & - & - & - & 0.29 & - & 0,51 & 0,38 & - & - & - & - & . & - & 0,26 & 0,27 & - & - \\
\hline
\end{tabular}




\begin{tabular}{|c|c|c|c|c|c|c|c|c|c|c|c|c|c|c|c|c|c|c|c|c|c|}
\hline \multirow{2}{*}{$\begin{array}{l}\text { Amostras/ } \\
\text { Ejementos }\end{array}$} & \multicolumn{6}{|c|}{ Complexo Ilhezus (CI) } & \multicolumn{15}{|c|}{ Complexo Săo José (CSJ) } \\
\hline & $\begin{array}{l}\text { JB- } \\
66\end{array}$ & $\begin{array}{c}\text { JB- } \\
\text { 313B }\end{array}$ & $\begin{array}{l}\text { JB- } \\
151 B\end{array}$ & $\begin{array}{l}\text { JB- } \\
239 \mathrm{~A}\end{array}$ & $\begin{array}{c}\text { JA- } \\
276 \mathrm{~A}\end{array}$ & $\begin{array}{l}\text { JB- } \\
28\end{array}$ & $\begin{array}{l}\text { JB- } \\
85\end{array}$ & $\begin{array}{l}\text { JB- } \\
71\end{array}$ & $\begin{array}{c}\text { JB- } \\
239 \mathrm{~A}\end{array}$ & $\begin{array}{l}\text { JB- } \\
\text { 313A }\end{array}$ & $\begin{array}{l}\text { JB- } \\
151 A\end{array}$ & $\begin{array}{l}\text { JB- } \\
146\end{array}$ & $\begin{array}{l}\text { JB- } \\
312\end{array}$ & $\begin{array}{l}\text { JB- } \\
117\end{array}$ & $\begin{array}{l}\text { JE- } \\
273\end{array}$ & $\begin{array}{l}\text { JB- } \\
272\end{array}$ & $\begin{array}{l}\text { JB- } \\
99\end{array}$ & $\begin{array}{l}\text { JB- } \\
86\end{array}$ & $\begin{array}{l}\text { JB- } \\
87\end{array}$ & $\begin{array}{l}\text { JB- } \\
106\end{array}$ & $\begin{array}{l}\text { JB- } \\
233\end{array}$ \\
\hline $\mathrm{SiO}_{2} \%$ & 48,60 & 49,20 & 49,90 & 52,00 & 53.70 & 54,10 & 56,10 & 59,80 & 61,70 & 63,30 & 66,20 & 71,20 & 71,70 & 54,70 & 56.80 & 58,00 & 59,70 & 59,90 & 59,90 & 57,80 & 64,70 \\
\hline $\mathrm{Al}_{2} \mathrm{O}_{1} \%$ & 13,20 & 13,10 & 15,60 & 13,30 & 13,20 & 15,00 & 17,30 & 15,60 & 17,10 & 16,10 & 14,20 & 13,20 & 14,80 & 17,00 & 13,80 & 14,80 & 14,20 & 14.20 & 14,60 & 15,20 & 15,60 \\
\hline $\mathrm{Fe}_{2} \mathrm{O}_{3} \%$ & 4,60 & 8,09 & 1,90 & 5,16 & 5,55 & 4,57 & 3,69 & 1,70 & 1,90 & 3,05 & 1,10 & 1,30 & 0,95 & 3,11 & 3,08 & 2,73 & 1,40 & 2,77 & 0,99 & 4,30 & 4,47 \\
\hline FeO $\%$ & 11,70 & 7,56 & 8,90 & 9,32 & 7,87 & 4,83 & 6,56 & 6,30 & 3,04 & 2,90 & 3,90 & 2,10 & 0,55 & 4,00 & 4,14 & 3.66 & 4,60 & 2,76 & 4,10 & 3,31 & 2,35 \\
\hline $\mathrm{MnO} \%$ & 0,19 & 0,21 & 0,19 & 0,21 & 0,15 & 0,11 & 0,12 & 0,06 & 0,05 & 0,06 & $<0,05$ & 0,02 & 0,09 & 0,09 & 0,08 & 0,09 & 0,05 & 0,08 & 0,08 & 0,06 & 0,05 \\
\hline Mgo \% & 5,60 & 6,71 & 6,30 & 6,20 & 5,66 & 6,28 & 2,23 & 3,00 & 1,50 & 2,03 & 1,70 & 1,50 & 0,95 & 3,84 & 5,10 & 4,00 & 4,00 & 3,43 & 3,60 & 2,38 & 1,29 \\
\hline $\mathrm{CaO} \%$ & 9,80 & 10,20 & 10,90 & 9,49 & 9,28 & 11,10 & 8,74 & 4,80 & 5,73 & 4,73 & 3,90 & 3,10 & 4,03 & 7,55 & 6,93 & 6,06 & 4,60 & 5,46 & 4,80 & 6,12 & 3,60 \\
\hline $\mathrm{Na}_{2} \mathrm{O} \%$ & 2,70 & 2,98 & 2,80 & 2,57 & 3,30 & 3,96 & 3,86 & 4,00 & 4,53 & 4,44 & 3,80 & 4,30 & 4,10 & 4,27 & 3,32 & 3,77 & 3,99 & 3,42 & 4,10 & 3,67 & 3,92 \\
\hline $\mathrm{K}_{2} \mathrm{O} \%$ & 0,41 & 0,80 & 0,48 & 0,98 & 1,24 & 0,67 & 1,26 & 1,60 & 1,98 & 1,55 & 2,10 & 1,30 & 1,37 & 3,40 & 4,51 & 4,70 & 4,80 & 4,76 & 4,80 & 3,93 & 4,59 \\
\hline $\mathrm{TiO}_{2} \%$ & 2,20 & 2,04 & 1,60 & 0,99 & 1,32 & 0,59 & 1,13 & 1,20 & 1,64 & 0,86 & 1,30 & 0,37 & 0,11 & 1,30 & 1,29 & 1,23 & 1,00 & 1,00 & 0,93 & 2,17 & 0,72 \\
\hline $\mathrm{P}_{2} \mathrm{O}_{5} \%$ & 0,42 & $<0,10$ & 0,21 & 0,10 & $<0,10$ & 0,10 & 0,13 & 0,37 & 0,22 & 0,13 & 0,36 & 0,05 & $<0,10$ & 0,91 & 1,13 & 0,94 . & 0,99 & 0,87 & 1,00 & 1,03 & 0,11 \\
\hline $\mathrm{H}_{2} \mathrm{O} \%$ & 0,20 & 0,08 & 0,20 & 0,12 & 0,07 & - & 0,04 & 0,20 & 0,17 & 0,18 & 0,10 & 0,20 & 0,19 & 0,10 & $<0,10$ & $<0,10$ & 0,30 & 0,27 & 0,20 & 0,18 & $<0,10$ \\
\hline P.F & $<0,01$ & 0,01 & 0,70 & - & 0,21 & 0,17 & - & 1,20 & 0,31 & 0,57 & 0,80 & 0,80 & 0,74 & 0,22 & - & 0,11 & 0,30 & 0,71 & 0,40 & 0,53 & 0,51 \\
\hline TOTAL. & 99,62 & 101,08 & 99,68 & 100,44 & 101,71 & 101,52 & 101,15 & 99,89 & 99,88 & 99,89 & 99,57 & 99,47 & 99,61 & 100,49 & 100,29 & 100,18 & 99,88 & 99,78 & 99,50 & 100,68 & 102,01 \\
\hline Cu ppm & 220,00 & 45,00 & 46,00 & 55,00 & 145,00 & 135,00 & 35,00 & 76,00 & 20,00 & 60,00 & 8,00 & 21,00 & 10,00 & 35,00 & 45,00 & 40,00 & 25,00 & 105,00 & 31,00 & 25,00 & 15,00 \\
\hline $\mathrm{Pb} \mathrm{ppm}$ & 12,00 & 20,00 & $<4,00$ & 20,00 & 20,00 & 30,00 & 20,00 & 18,00 & 20,00 & 30.00 & 10,00 & 4,00 & 20,00 & 40,00 & 40,00 & 50,00 & 20,00 & 50,00 & 20,00 & 40,00 & 30,00 \\
\hline $\mathrm{Zn} \mathrm{ppm}$ & 36,00 & 115,00 & 14,00 & 155,00 & 115,00 & 75,00 & 110,00 & 56,00 & 60,00 & 80,00 & 38,00 & 26,00 & 20,00 & 85,00 & 90,00 & 85,00 & 15,00 & 75,00 & 15,00 & 105,00 & 65,00 \\
\hline Co ppm & 32,00 & 50,00 & 14,00 & 60,00 & $50, m 0$ & 45,00 & 30,00 & 17,00 & 20,00 & 10,00 & 5,00 & 6,00 & 5,00 & 25,00 & 30,00 & 25,00 & 6,00 & 15,00 & $6, \infty$ & 25,00 & 10,00 \\
\hline $\mathrm{Cr}_{\mathrm{ppm}}$ & 70,00 & 200,00 & 130,00 & $<50,0$ & 150,00 & 200,00 & 150,00 & 40,00 & $<50,0$ & 50,00 & $<50,00$ & 50,00 & 50,00 & 125,00 & 200,00 & 175,00 & 130,00 & 125,00 & 105,00 & 75,00 & $<50,0$ \\
\hline Ni ppm & 62,00 & 50,00 & 29,00 & 100,00 & 110,00 & 200,00 & 110,00 & 36,00 & 15,00 & 5,00 & 7,00 & 14,00 & 20,00 & 25,00 & 110,00 & 95,00 & 48,00 & 90,00 & 48,00 & 35,00 & 10,00 \\
\hline V ppm & 310,00 & 300,00 & 200,00 & 220,00 & 260,00 & 120,00 & 160,00 & 500,00 & 80,00 & 60,00 & 30,00 & 20,00 & $<20,00$ & 100,00 & 100,00 & 100,00 & 50,00 & 120,00 & 70,00 & 100,00 & 40,00 \\
\hline $\begin{array}{l}\text { Ba ppm } \\
\text { Sr ppm }\end{array}$ & $\begin{array}{l}640,60 \\
114,60\end{array}$ & $\begin{array}{l}1.660 \\
142,00\end{array}$ & $\begin{array}{l}300,00 \\
317,00\end{array}$ & $\begin{array}{l}2.800 \\
129,00\end{array}$ & $\begin{array}{l}3.500 \\
265,00\end{array}$ & $\begin{array}{l}2.200 \\
420,00\end{array}$ & $\begin{array}{c}3.350 \\
339,00\end{array}$ & $\begin{array}{l}550,00 \\
413,00\end{array}$ & $\begin{array}{l}3.350 \\
622,00\end{array}$ & $\begin{array}{l}2.250 \\
522,00\end{array}$ & $\begin{array}{l}1.250 \\
140,00\end{array}$ & $\begin{array}{l}1.100 \\
502,00\end{array}$ & $\begin{array}{l}1.300 \\
733,00\end{array}$ & $\begin{array}{l}5.000 \\
788,00\end{array}$ & $\begin{array}{l}6.450 \\
1.000\end{array}$ & $\begin{array}{l}5.400 \\
1.000\end{array}$ & $\begin{array}{l}2.500 \\
842,00\end{array}$ & $\begin{array}{l}3.650 \\
890,00\end{array}$ & $\begin{array}{l}2.700 \\
873,00\end{array}$ & $\begin{array}{l}4.350 \\
<1000\end{array}$ & $\begin{array}{l}3.500 \\
490,00\end{array}$ \\
\hline Rb ppm & 40,00 & $<0,10$ & 49,00 & $<10,0$ & 10,00 & 10,00 & 17,00 & 21,00 & $<10,00$ & $<10,0$ & $<10,0$ & 12,00 & $<10,00$ & 96,00 & 101.00 & 108,00 & 157,00 & 171,00 & 187,00 & 53,00 & 91,00 \\
\hline $\mathrm{Zr} \mathrm{ppm}$ & 124,00 & 89,00 & 494,00 & 26.00 & 95,00 & 30,00 & 223,00 & 285,00 & 239,00 & 486,00 & 89.00 & 572,00 & 134,00 & 447,00 & 132,00 & 123,00 & 176,00 & 248,00 & 233,00 & 368,00 & 396,00 \\
\hline $\mathrm{Nb}$ ppm & 13,00 & $<10,0$ & $<10,0$ & $<10,0$ & 10,00 & 10,00 & 10,00 & $<10,0$ & $<10,0$ & $<10,0$ & $<10,0$ & $<10,0$ & $<10,0$ & $<10,0$ & $<10,0$ & $<10,0$ & $<10,0$ & $<10,0$ & $<10,0$ & $<10,0$ & $<10,0$ \\
\hline Y ppm & 23,00 & 358,00 & $<10,0$ & 20,00 & 35,00 & 20,00 & 56,00 & 30,00 & $<10,00$ & 19,00 & 18,00 & $<10,0$ & $<10,0$ & 39,00 & 35,00 & 34,00 & 25,00 & 30,00 & 28,00 & 47,00 & 12,00 \\
\hline Ti $\mathrm{ppm}$ & 131,86 & 12227 & 9590 & - & - & - & - & - & - & - & - & - & - & - & - & - & - & - & - & - & - \\
\hline La ppm & - & - & - & - & - & - & 49,15 & - & - & - & - & 24,83 & - & - & 102,70 & 96,03 & - & - & 91,61 & 158,00 & 45,81 \\
\hline Ce ppm & - & - & - & - & - & - & 89,16 & - & - & - & - & 41,37 & - & - & 191,20 & 171,80 & - & - & 164,80 & 298,20 & 66,33 \\
\hline Nd ppm & - & - & - & - & - & - & 44,85 & - & - & - & - & 22,16 & - & - & 104,90 & 93.84 & - & - & 87,79 & 164,20 & 31,78 \\
\hline Sm ppm & - & - & - & - & - & - & 8,06 & - & - & - & - & 3,64 & - & - & 17,83 & 14,92 & - & - & 13,70 & 25,44 & 5,50 \\
\hline Eu ppm & - & - & - & - & - & - & 1,43 & - & - & - & - & 1,36 & - & . & 3,83 & 3,48 & - & - & 2,87 & 4,26 & 1,24 \\
\hline Gd ppm & - & - & - & - & - & - & 6,03 & - & - & - & - & 2.75 & - & - & 11,16 & 9,47 & - & - & 9,02 & 15,84 & 4,51 \\
\hline Dy ppm & - & - & - & 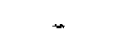 & - & - & 4,52 & - & - & - & - & 1,93 & - & - & 5,39 & 4,58 & - & - & 4,42 & 7,75 & 3,40 \\
\hline Er ppm & - & - & - & - & - & - & 2,77 & - & - & - & - & 0,89 & - & - & 2,51 & 1,98 & - & - & 1,94 & 3,05 & 1,12 \\
\hline Yb ppm & - & - & - & - & - & - & 2,26 & - & - & - & - & 0,74 & - & - & 1,50 & 1.27 & - & - & 1.25 & 1,78 & 0.76 \\
\hline Lu ppm & - & - & - & - & - & - & 0,34 & - & - & - & - & 0,10 & - & - & 0,24 & 0,23 & - & - & 0,17 & 0,24 & 0,10 \\
\hline
\end{tabular}




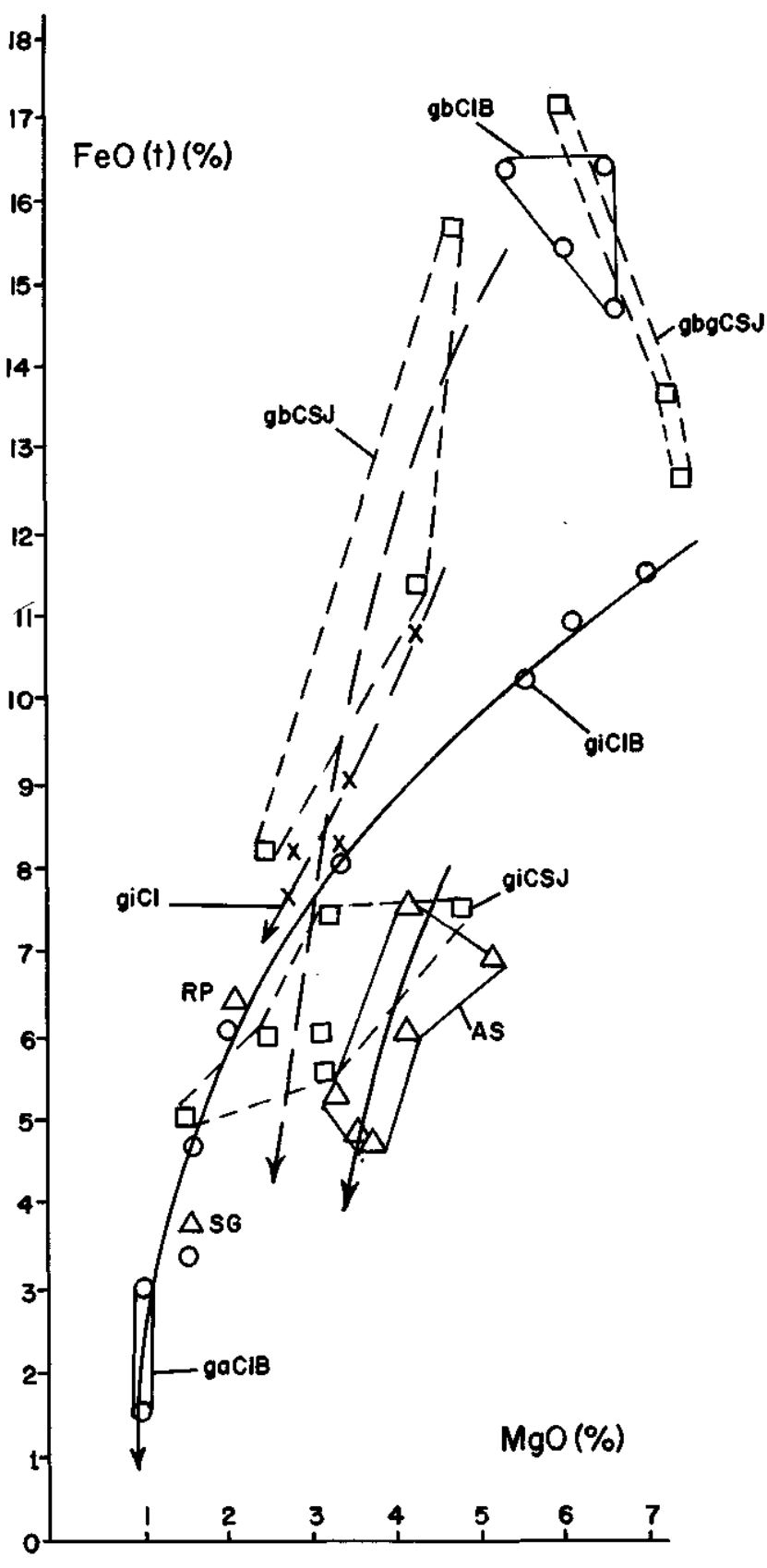

Figura 7 - Litologias da área de estudo no diagrama binário $\mathrm{FeO}$ × $\mathrm{MgO}$. Verificar que os trends cálcio-alcalino dos granulitos básicos e intermediários do Complexo São José (CSJ) e cálcio-alcalino dos granulitos intermediários e ácidos do Complexo Ibicaraí-Buerarema (CIE) localizam-se em posições distintas no diagrama. Os granulitos básicos destes mesmos complexos situam-se deslocados destes trends. Mesma simbologia da figure 3

Figure 7 - Plot of the lithologies of the study area on the $\mathrm{FeO} \times \mathrm{MgO}$ binary diagram. Note that the calc-alkaline trends of the basic and intermediate granulites of the São José Complex (CSJ) and of the intermediate and acid granulites of the Ibicaraí-Buerarema Complex (CIB) plot on different positions on the diagram. The basic granulites of these complexes are offset with respect to these trends. Same simbology of figure 3

granulitos básicos com granada podem ser também classificados como metaluminosos (Fig. 5) e semelhantes a basaltos/gabros de fundo oceânico ou de bacia pós-arco, isto se for levado em conta os conteúdos de Ti, Zr e Cr (Fig. 12,

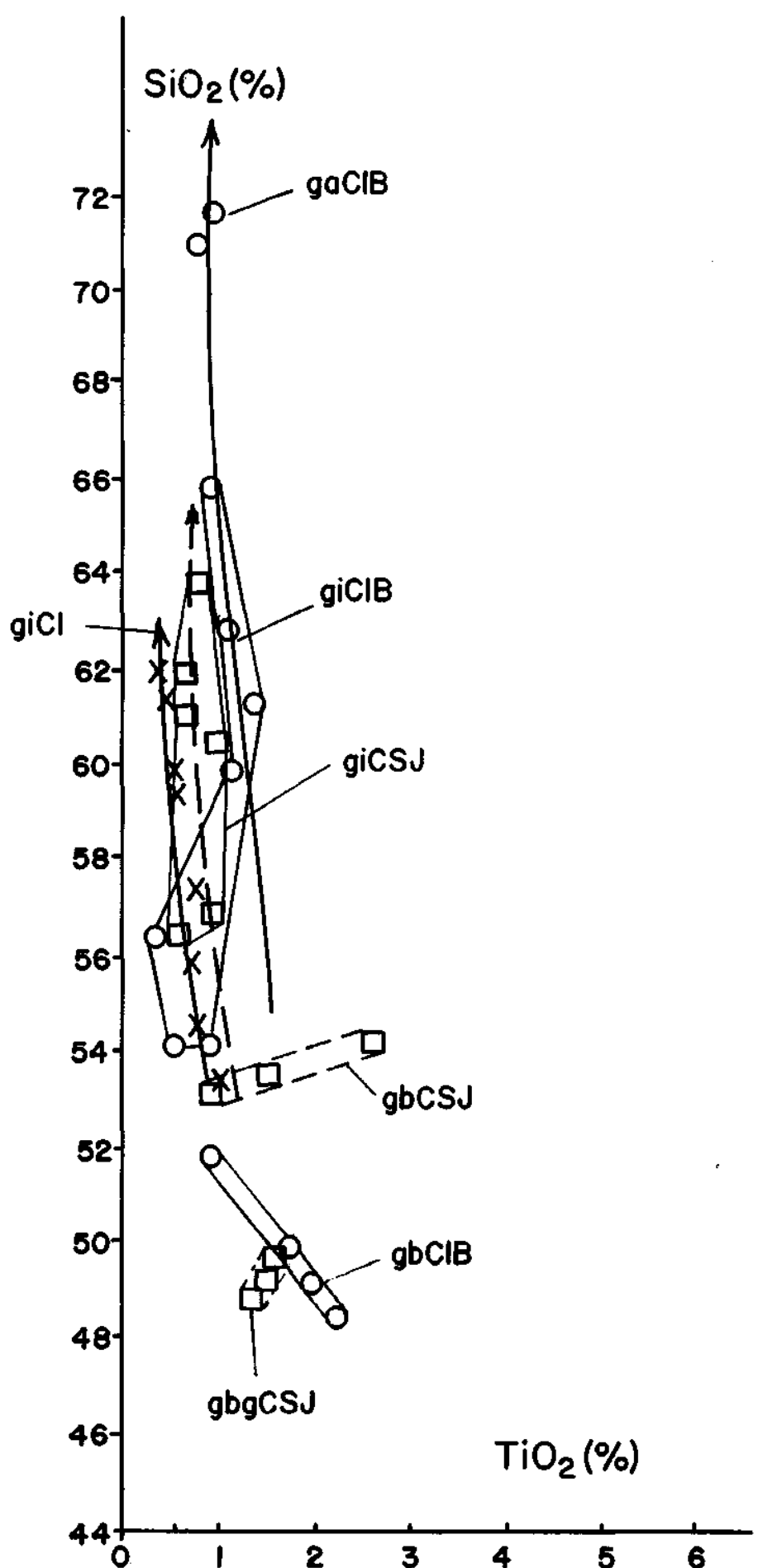

Figura 8 - Diagrama $\mathrm{SiO}_{2} \times \mathrm{TiO}_{2}$ para as rochas da área pesquisada. Os trends cálcio-alcalino de baixo $\mathrm{K}$ dos Complexos São José (CSJ) e Ibicarai-Buerarema (CIB), além do trend cálcio-alcalino de alto $K$ do Complexo Ilhéus $(\mathrm{Cl})$, praticamente superpõem-se quando utilizados estes elementos. Entretanto, os granulitos básicos de filiação toleítica, situam-se deslocados destes trends. Mesma simbologia da figura 3

Figure 8 - Diagram $\mathrm{SiO}_{2} \times \mathrm{XiO}_{2}$ for the lithologies of the study area. The low-K calc-alkaline trends of the São José (CSJ) and the Ibicaraí-Buerarema (CIB) complexes and the high-K calc-alkaline trend of the Ilhéus Complex $(\mathrm{Cl})$, overlap when these elements are used. Notwithstanding, the basic granulites of tholeitic affiliation are offset with respect of these trends. Same simbology of figure 3 


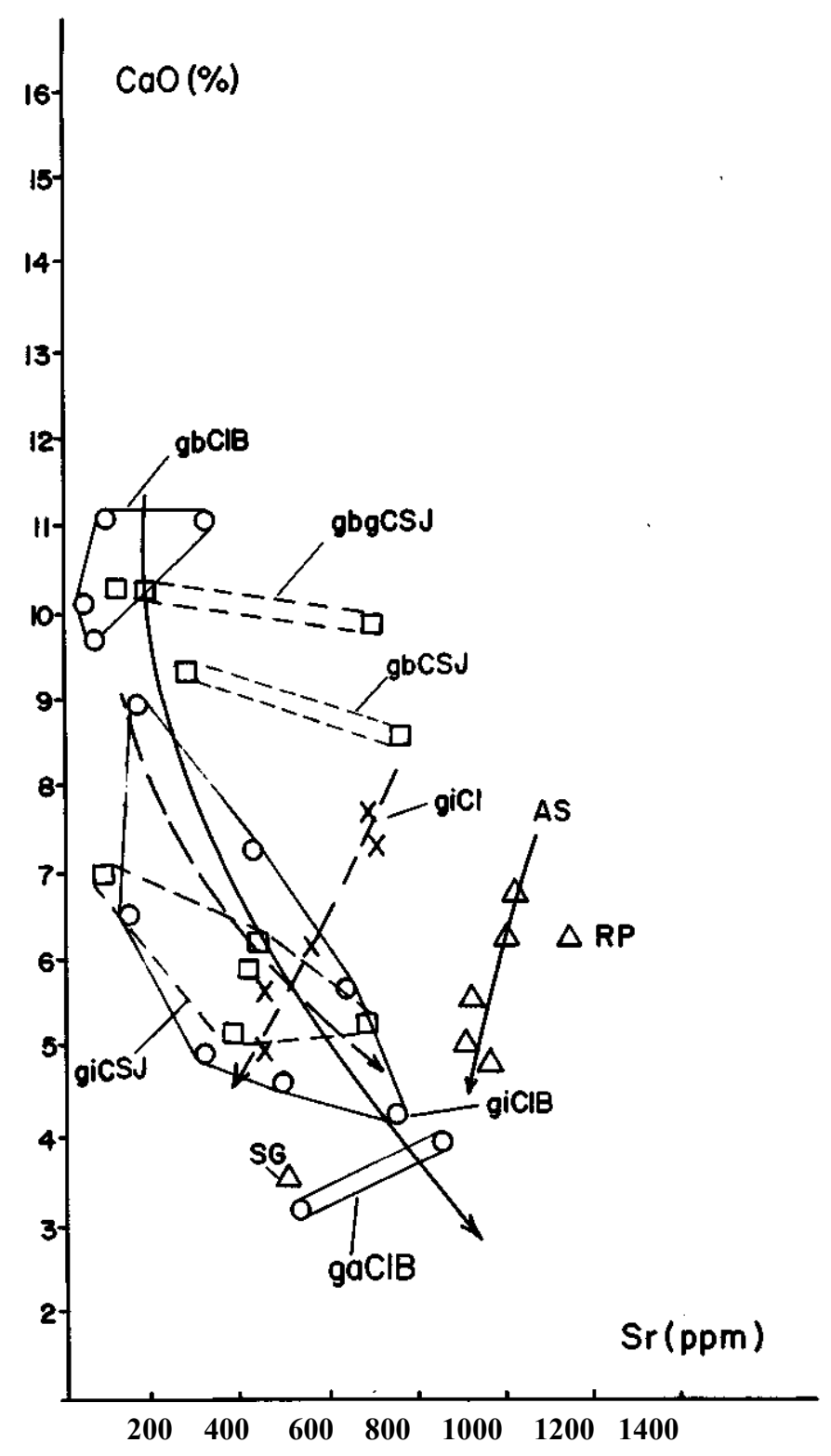

Figura 9 - Diagrama $\mathrm{CaO} \times \mathrm{Sr}$ para as rochas da área. Observar a discrepância entre as linhagens cálcio-alcalinas dos Complexos São José (CSJ) e Ibicarai-Buerarema (CIB), em relação aqueles dos Complexos Ilhéus (CI) e Granitóides Shoshoníticos/Alcalinos. Mesma simbologia da figura 3 Figure 9 - Diagram $\mathrm{CaO}$ x $\mathrm{Sr}$ for the lithologies of the study área. Note the discrepancy between the calc-alkaline lineages of the São José (CSJ) and the Ibicarai-Buerarema (CIB) complexes with respect to those of the Ilhéus complex (CI) and the shoshonitic/alkaline granitoids. Same simbology of figura 3

13, Tab. 2) e os teores de Terras Raras (Fig. 10, Tab. 2). Nas figuras $6,7,8$ e 9, os pontos de análises químicas desses granulitos básicos com granada situam-se com certo deslocamento em relação ao trend cálcio-alcalino de baixo $\mathrm{K}$ referido anteriormente. Todos estes dados levam a crer que os granulitos básicos com granada são toleíticos e, portanto, de filiação diferente das encaixantes cálcio-alcalinas, podendo ser interpretados como enclaves, dentro dessas últimas. Alternativamente, podem não ter sido enclaves mas "camadas" de basaltos/gabros, de uma possível crosta oceânica obductada, colocadas dentro das encaixantes cálcioalcalinas através de "fatias de cavalgamento", em virtude das intensas deformações e metamorfismo granulítico que atingiu a região de Itabuna.

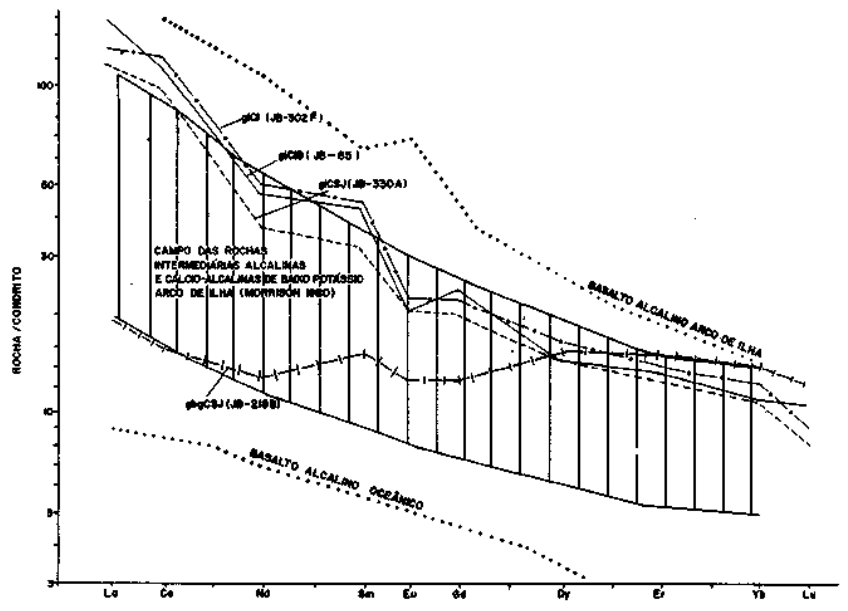

Figura 10 -Padrão de Terras Raras para rochas granuliticas da área pesquisada. Verificar a diferença entre as litologias cálcio-alcalinas daquela considerada como toleítica. Para comparação, foram inseridos padrões de Terras Raras de basaltos alcalinos e limitado o campo de rochas intermediárias, alcalinas e cálcio-alcalinas de baixo $K$ típicas de arcos insulares, segundo Morrison (1980)

Figure 10 - Rare Earth pattern for the granulitic rocks of the study area. Note the differences between the calc-alkaline and the tholeiitic lithologies. For purposes of comparison, the Rare Earth patterns of the alkaline basalts and the fields of island are's intermediate, alkaline and low-K calc-alkaline rocks were ploted on the same diagram by Morrison (1980)

Complexo Ibicaraí-Buerarema (CIB) Os granulitos intermediários e ácidos que constituem esse Complexo, no diagrama da figura 3 , posicionam-se desde o campo dos basaltos andesíticos/dioritos, até riolitos/ trondhjemitos, com os teores de $\mathrm{SiO}_{2}$ variando de 52 até cerca de $72 \%$, e as quantidades de $\mathrm{K}_{2} \mathrm{O}$ oscilando entre aproximadamente $1 \%$ até $1,6 \%$ (Tab. 2). Quimicamente, não diferem muito da sequência de rochas do Complexo São José, pois seus pontos representativos também se distribuem no campo da série cálcio-alcalina de baixo $\mathrm{K}$, tipo arco-de-ilha ou margem continental ativa (Fig. 3, 4 ), podendo ainda ser classificados como rochas meta-luminosas (Fig. 5). São litologias ricas em plagioclásio e quartzo, mas pobres em minerais ferro-magnesianos (Tab. 1). Nas figuras $6,7,8$ e 9, as amostras de granulitos intermediários e ácidos deste Complexo alinham-se relativamente bem sobre um trend de diferenciação também muito parecido com aquele definido para as rochas do Complexo São José, com a diferença que este possui termos mais básicos, enquanto o Complexo Ibicaraí-Buerarema é desprovido de granulitos básicos cogenéticos. Este, por sua vez, é portador de termos mais ácidos, os quais são inexistentes no Complexo São José. Com relação aos elementos Terras Raras, na figura 10 , pode-se notar o padrão cálcio-alcalino dos granulitos intermediários do Complexo Ibicaraí-Buerarema.

Registre-se, aqui, que Silva (1991) e Arcanjo et al. (1991) chamaram a atenção para o fato de que, tanto os granulitos intermediários desse Complexo como aqueles do Complexo São José, apresentam como uma das características teores altos em $\mathrm{A}_{2} \mathrm{O}_{3}$, superiores a $15 \%$ em peso (Tab. 2), podendo assim ser também classificados como tonalitos-trondhjemitos do tipo high-alumina encon-trados em terrenos arqueanos de alto grau metamórfico (Barker \& Arth 1976). As razões $\mathrm{K}_{2} \mathrm{O} / \mathrm{Na}_{2} \mathrm{O}$ (baixas, inferiores a 0,5 ), além das razões $\mathrm{K} / \mathrm{Ba}, \mathrm{Ba} / \mathrm{Rb}$ e $\mathrm{Rb} / \mathrm{Sr}$, exibidos por essas litologias de Itabuna, segundo dados do 


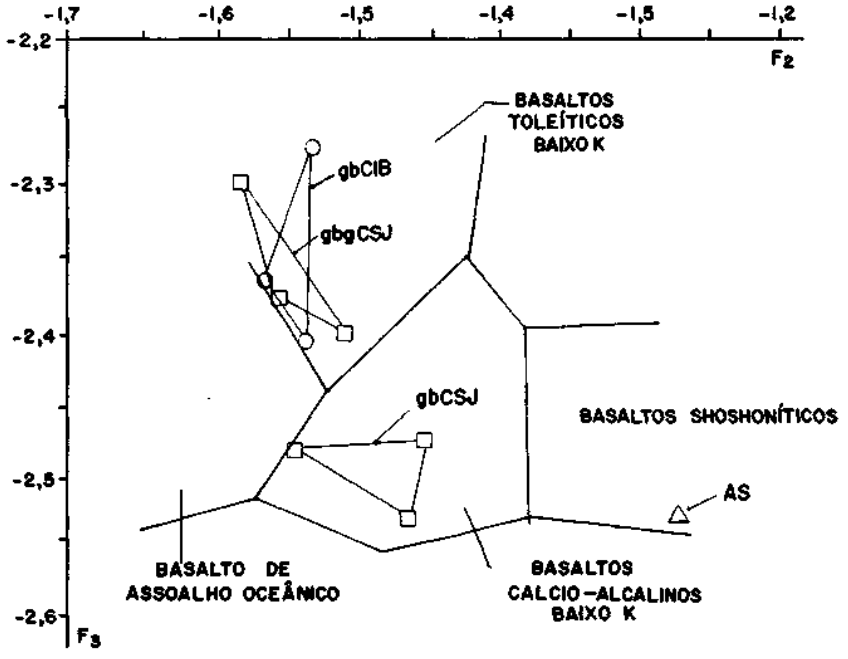

Figura 11 - Localização dos granulitos básicos da área, no diagrama de Pearce (1976), sendo F2 e F3 funções discriminantes estabelecidas por este autor. Observar que os granulitos básicos com granada do Complexo São José (CSJ) e granulitos básicos do Complexo Ibicaraí-Buerarema (CIB) situam-se no campo dos basaltos toleíticos de baixo potássio, enquanto granulitos básicos, sem granada do Complexo São José, situam-se no campo dos basaltos cálcio-alcalinos de baixo potássio. Uma amostra de um termo mais básico, do Granitóide Agua Sumida, localiza-se no campo shoshonítico do diagrama. Mesma simbologia da figura 3

Figure 11 - Plot of the basic granulites of the study area on the Pearce (1976) diagram. F2 and F3 are discriminant functions established by this author. Note that the garnet-bearing basic granulites of the São José Complex (CSJ) and the basic granulites of the Ibicaraí-Buerarema Complex (CIB) plot on the low-K tholeiitic basalts field, whereas the basic granulites of the São José Complex (CSJ) plot on low-K calcalkaline basalts field. A more basic sample of the Água Sumida granitoid plots on the shoshonitic field of the diagram. Same simbology of figure 3

trabalho de Tarney et al. (1972), caracteriza-as como do tipo empobrecido.

Ainda, vale destacar que, assim como no Complexo São José, no Complexo Ibicaraí-Buerarema também ocorrem granulitos básicos, sob a forma de bandas centimétricas a métricas, dispostas paralelamente à direção geral do bandamento/foliação da rocha. Quimicamente, podem ter sido originalmente basaltos ou gabros (Fig. 3), metaluminosos (Fig. 5), com características químicas semelhantes a basaltos ou gabros toleíticos, de fundo oceânico ou bacia pós-arco (Fig. 11, 12, 13; Tab. 2), diferente dos granulitos intermediários e ácidos encaixantes, que são de tendência cálcioalcalina (Fig. 3, 4, 6, 7, 8, 9).

As rochas do Complexo Rio Japu não foram analisadas quimicamente, não sendo por isso descritas neste trabalho.

Granitóides Água Sumida (AS), Rio Paraíso (RP) e São Geraldo (SG) Os monzodioritos, monzonitos, sienitos e granitos, todos reequilibrados na fácies granulito, quando estudados em termos dos teores de $\mathrm{K}_{2} \mathrm{O}$ e $\mathrm{SiO}_{2}$, distribuem-se, no diagrama de Peccerillo \& Taylor (1976), no campo das rochas shoshoníticas, sobretudo os gontos representativos das análises químicas do corpo Ågua Sumida (Fig. 3,4,11). Esses granitóides também são metaluminosos, como todas as rochas granulíticas da região de Itabuna (Fig. 5), apesar desses metamonzodioritos,

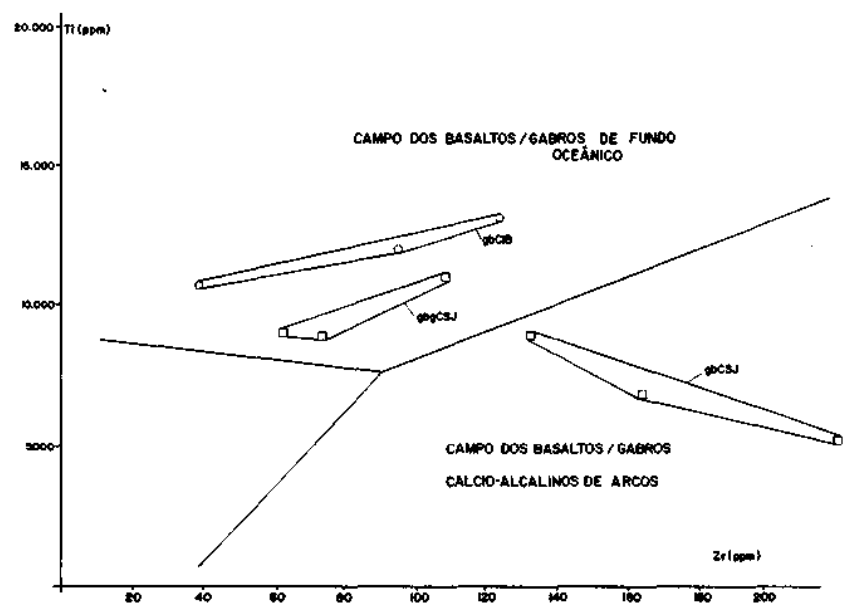

Figura 12 - Localização dos granulitos básicos da área no diagrama de Pearce \& Cann (1973). Verificar que amostras dos granulitos básicos com granada do Complexo São José (CSJ) e granulitos básicos do Complexo Ibicaraí-Buerarema (CIB) situam-se no campo dos basaltos/gabros de fundo oceânico ou bacia pós-arco. Por sua vez, granulitos básicos do Complexo São José localizam-se no campo dos basaltos/gabros cálcio-alcalinos de arcos ou margem continental ativa. Mesma simbologia da figure 3

Figure 12 - Plot of the basic granulites of the study area on the Pearce \& Cann (1973) diagram. Note that the garnet-bearing basic granulites of the São José Complex (CSJ) and the basic granulites of the IbicaraíBuerarema Complex (CIB) plot on the ocean-floor basalt/gabro and the back-arc basin fields. On the other hand, the basic granulites of the São José Complex plot on the field of the calc-alkaline basalt/gabbro of island are or active continental margin affiliation. Same simbology of figure 3

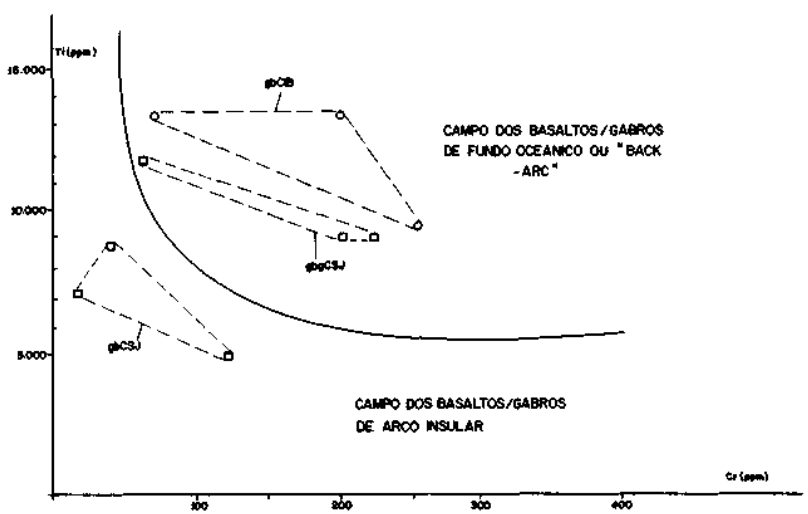

Figura 13 - Distribuição de amostras de granulitos básicos da área pesquisada no diagrama de Pearce (1975). As mesmas observações da figura 12 são válidas para esta figura. Mesma simbologia da figura 3

Figure 13 - Pior of the basic granulite lithologies of the study area on the Pearce (1975) diagram. The comments in the caption of figure 12 are also valid for this figure. Same simbology of figure 3

metamonzonitos e metasienitos exibirem química diferente em relação aos elementos $\mathrm{CaO}, \mathrm{Na}_{2} \mathrm{O}, \mathrm{FeO}, \mathrm{MgO}, \mathrm{TiO}_{2}$ (Fig. 6, 7, 8, 9) e, principalmente, em relação aos elementos traços e Terras Raras (Tab. 2). As figuras 14 e 15, por sua vez, demonstram a grande semelhança das litologias que compõem esses granitóides, com aquelas vulcânicas e 

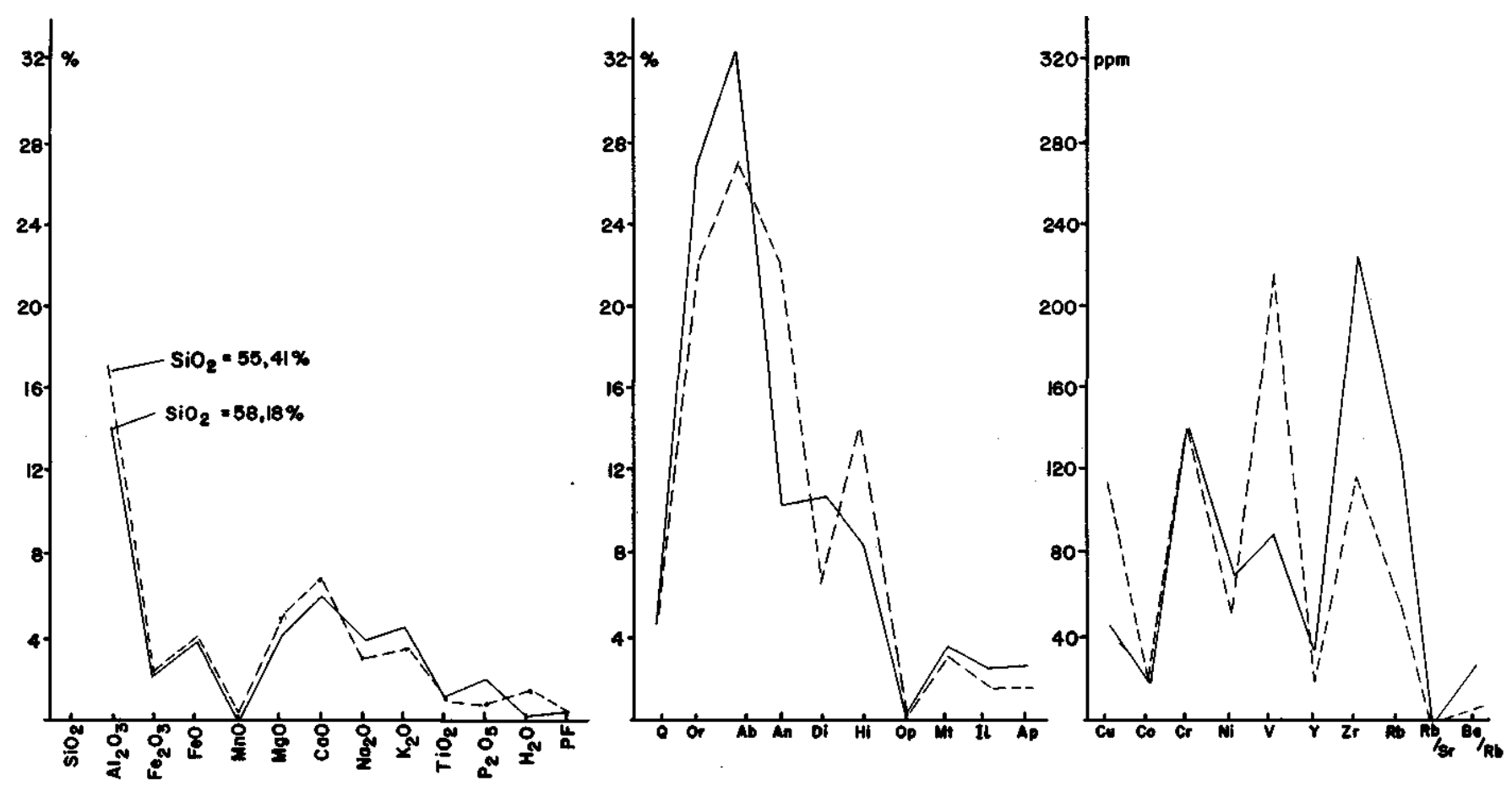

Figura 14 - Diagrama comparativo dos granitóides da área com rochas shoshoníticas de arcos insulares. As linhas tracejadas representam a média de 22 análises de elementos maiores, análises modais e elementos traços de rochas vulcânicas e plutônicas shoshoníticas, tipo arcos-de-ilhas e margens continentais ativas. As linhas cheias correspondem a média de seis análises e composição modal dos granitóides shoshoniticos da área pesquisada

Figure 14 - Comparative diagram of the granitoids of the study area with island are shoshonitic rocks. The broken lines represent the average of 22 determinations of major elements, modal analysis and trace elements of volcanic and plutonic shoshonitic rocks, of the island are and active continental margin type. The continuous lines represent the average of six analysis and modal composition of shoshonitic granitoid rocks of the study area

plutônicas de arcos-de-ilhas ou margens continentais ativas de outras partes do mundo.

DISCUSSÕES E CONCLUSÕES O estudo petroquímico das rochas granulíticas da região de Itabuna possibilitou interpretações com relação às características dos protólitos pré-granulitização. Conseguiu-se deduzir que todas as litologias originais tiveram origem magmática, embora não tenha sido possível identificar quimicamente se foram vulcânicas ou plutônicas, face às intensas deformações e recristalizações metamórficas a que foram submetidas. Somente em alguns casos os aspectos de campo e texturais permitiram essa identificação.

Possíveis basaltos e/ou gabros toleíticos, de fundo oceânico ou bacia pós-arco, foram interpretados a partir do estudo geoquímico dos granulitos básicos com granada do Complexo São José e os granulitos básicos do Complexo Ibicaraí-Buerarema.

Ainda com relação a estes dois Complexos, algumas bandas básicas sem granada e os granulitos intermediários do São José foram considerados, antes da granulitização, como possíveis basaltos andesíticos e/ou dioritos e andesitos e/ou quartzo-diorito, respectivamente; do IbicaraíBuerarema, seus granulitos intermediários e ácidos, possivelmente, são os representantes metamorfizados, em alto grau, de basaltos andesíticos e/ou dioritos, andesitos e/ou quartzo-dioritos, dacitos e/ou tonalitos e riolitos e/ou trondhjemitos. Tanto os granulitos básicos sem granada e intermediários do São José como os intermediários e ácidos do Ibicaraí-Buerarema, foram considerados de filiação cálcio-alcalina de baixo potássio, semelhante às rochas encontradas em arco-de-ilhas ou margens continentais ativas. Tudo indica que faziam parte de duas sequências comagmáticas, com ligeiras diferenças químicas entre elas, sendo que os termos intermediários meta-andesitos e/ou metadioritos, além dos metadacitos e/ou metatonalitos, foram predominantes em ambas.

As rochas do Complexo Ilhéus não tiveram seus granulitos básicos estudados; entretanto, os granulitos intermediários, quando analisados do ponto de vista químico, mostram semelhanças com rochas cálcio-alcalinas, como as anteriores, com a diferença que neste caso são mais ricas em potássio e em outros elementos incompatíveis. Antes do reequilíbrio, na fácies granulito, foram provavelmente rochas do tipo andesito e/ou quartzo-dioritos.

Os corpos plutônicos de Água Sumida, Rio Paraíso e São Geraldo são monzodioritos, monzonitos, sienitos e granitos. Todas essas litologias foram deformadas e recristalizadas na fácies granulito, mostrando, algumas vezes, em uma mesma lâmina delgada, duas duplas de opxcpx: (i) a primeira, constituída de cristais maiores, zonados e com lamelas de exsolução, provavelmente plutônica, parcialmente preservada da granulitização; e (ii) a segunda, representada por cristais menores, orientados paralelamente à foliação, sem zoneamento e sem lamelas, considerada como cristalizada durante o metamorfismo granulítico (Barbosa 1990, 1991, Barbosa et al. 1992). Todas essas litologias plutônicas, estudadas geoquimicamente, mostraram ser comparáveis a rochas de filiação shoshonítica ou mesmo alcalina.

As rochas da região de Itabuna parecem ser semelhantes àquelas encontradas ao norte, no Domínio da Costa Atlântica (Barbosa 1986), e consideradas como fazendo parte de um suposto conjunto de arco-de-ilha/bacia pós-arco (Barbosa 1990,1991 ) de idade proterozóica-inferior (Alibert \& Barbosa 1992, Marinho et al. 1992), profundamente erodido, ou uma margem continental ativa (Figueiredo 1989, Figueiredo \& Barbosa 1992). Este conjunto arco/bacia pós-arco 


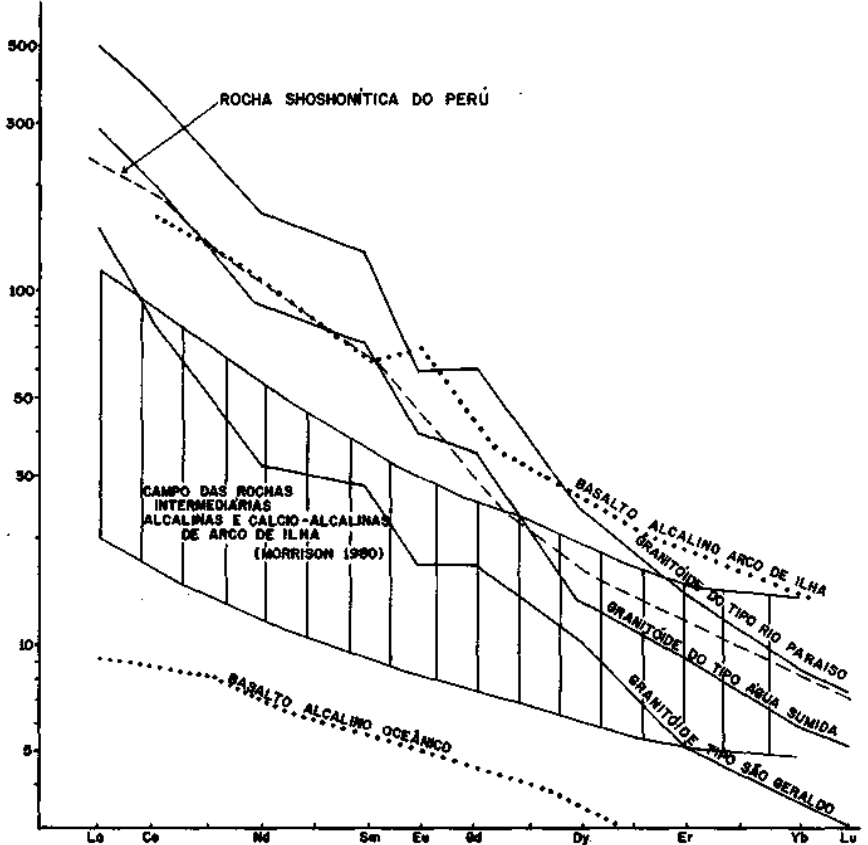

Figura 15 -Padrões normalizados por condrito (Masuda et al. 1973), de Terras Raras para os granitóides da área. Para todos os tipos, verifica-se padrão semelhante àqueles considerados shoshoniticos. Para comparação, foram colocados na figura padrões de Terras Raras de basaltos alcalinos, campo das rochas alcalinas e cálcio-alcalinas de arcos insulares (Morrison 1980), além de um padrão de uma rocha shoshonítica do Peru (Dostal et al. 1977). Esta última e os granitóides da área mostram grande semelhança quanto aos teores de Terras Raras

Figure 15 - Crondrite normalized (Masuda et al. 1973) rare earth pattern for the granitoids of the study area. All granitoids show a shoshonitic type pattern. For comparison were plotted on the same figure, the Rare Earth patterns of alkaline basalts, and alkaline and calc-alkaline rocks of island are affilliation (Morrison 1980). Also plotted is the pattern for a shoshonitic rock from Peru (Dostal et al. 1977). This sample and the granitoids of the study area show great similarity concerning their content of Rare Earth elements

poderia ter sido produzido pela subducção de uma suposta placa oceânica situada na parte mais oriental do Domínio da Costa Atlântica e com vergência para oeste.

\section{REFERÊNCIAS BIBLIOGRÁFICAS}

AILLON, M.P. \& BARBOSA, J.S.F. 1992. As rochas metamórficas de alto grau da região de Cachoeira, São Felix e Cruz das Almas - Bahia. In: SIMPOSIO REG. GEOL. BAHIA-SERGIPE, 1. Salvador, 1992. Anais... Salvador, SBG. v. 1, p. 96-99.

ALIBERT, C. \& BARBOSA, J.S.F. 1992. Ages U-Pb determines à Ia "SHRIMP" sur des zircons du Complex de Jequié, Craton du São Francisco, Bahia, Brésil. In: REUNION DES SCIENCES DE LA TERRE, 14. Toulouse, 1992. Anais. Toulouse, Franca, p. 4.

ALMEIDA, F.F.M. 1977. O Craton do São Francisco. Rev. Bras. Geoc., 7(4):349-364.

ARCANJO, J.B.A.; OLIVEIRA, J.E.; GOMES, R.A.A.D.; MENESES, N.R., $F^{\circ}$; TEIXEIRA, L.R.; SOUZA, J.D.; PADILHA, A.V.; DELGADO, I.M.; SANTOS, R.A.; MELO, R.C.; FERNANDES, P.C. d'A. 1991. Geologia da Região Sul do Estado da Bahia: Itabuna, Folha SD.24-Y-B-VI; Estado da Bahia. Texto Explicativo. Brasília, DNPM/CPRM. p. 1-332.

ARCANJO, JB.A.; BARBOSA, JS.F. OLIVEIRA, JE. 1992. Caracterização petrográfica e metamórfica dos granulitos arqueanos/proterozóicos inferiores da região de Itabuna-Bahia. Rev. Bras. Geoc., 22(1):47-55

BARBOSA, J.S.F. 1986. Constitution Lithologique et Metamorphique de la Region Granulitique du Sud de Bahia - Brésil. França. Paris VI). Inédito).
Assim, com base na similaridade dessas rochas, podese considerar que: (i) os granulitos básicos com granada do Complexo São José e os granulitos básicos do Complexo Ibicaraí-Buerarema (Fig. 2) são correlacionáveis aos granulitos básicos com granada de Barbosa (1986, 1990, 1991), cujos protólitos foram basaltos/gabros toleíticos de fundo oceânico ou bacia pós-arco; (ii) as bandas de granulitos básicos sem granada, granulitos intermediários e ácidos dos Complexos São José e Ibicaraí-Buerarema, constituem a continuação sul dos granulitos intermediários e ácidos de Barbosa (1990, 1991), Figueiredo (1989) e Figueiredo \& Barbosa (1992) que, segundo estes autores, tiveram como rochas originais, pré-metamórficas, sequências magmáticas diferenciadas, cálcio-alcalinas, baixo potássio, tipo arco-de-ilha ou margem ativa, formada de andesitos basálticos e/ou dioritos, andesitos e/ou quartzo-dioritos, dacitos e/ou tonalitos, riolitos e/ou trondhjemitos; e (iii) os Granitóides Água Sumida, Rio Paraíso e São Geraldo são os correspondentes meridionais das rochas descritas por Barbosa (1986, 1989, 1990, 1991) e Barbosa et al. (1992a/b), no Domínio da Costa Atlântica, como provenientes de magmas shoshoníticosalcalinos.

As rochas intermediárias do Complexo Ilhéus, como foi mostrado anteriormente, possuem características cálcio-alcalinas de alto potássio, sendo também comparáveis com aquelas encontradas em arcos-de-ilhas ou margem continental ativa, vindo compor o quadro geotectônico estabelecido para o Domínio da Costa Atlântica.

Assim, semelhantemente ao que ocorreu nos processos evolutivos de formação deste Domínio (Barbosa 1990, 1991), as rochas da região de Itabuna, com idades provavelmente mais novas que $2,4 \mathrm{Ga}$ (Marinho et al. 1992), também teriam sidos obductadas sobre um proto-continente (Domínio Jequié-Mutuípe-Maracás de Barbosa et al. 1992a, 1992b), mais antigo e situado a oeste do Domínio da Costa Atlântica. Finalmente, as principais fases de deformação e o metamorfismo principal impostos nas rochas em questão foram possivelmente provocados por processos ligados a essa colisão/obducção (Barbosa 1990, 1991, Figueiredo \& Barbosa 1992, Barbosa et al. 1992a, 1992b).

Agradecimentos Os autores agradecem ao geólogo Geraldo V.V. Souza pela revisão do texto e ao Professor Herbet Conceição pela leitura e críticas apresentadas ao manuscrito. Também são gratos à Companhia de Pesquisa de Recursos Minerais (CPRM) e ao Conselho Nacional de Desenvolvimento Científico e Tecnológico ( $\mathrm{CNPq})$, que permitiram a realização dessas pesquisas.

401. (Tese de Doutoramento, Université Pierre et Marie Curie,

BARBOSA, J.S.F. 1988. Principais geobarômetros utilizados em granulitos: análise dos resultados de um exemplo do Sul da Bahia - Brasil. Rev. Bras. Geoc., 18(2):162-169.

BARBOSA, J.S.F. 1989. Química mineral utilizada na identificação das fácies metamórficas da região granulítica do Sul da Bahia. Rev. Bras. Geoc. 19(3):350-366.

BARBOSA, J.S.F. 1990. The granulites of the Jequié-Complex and Atlantic Coast Mobile Belt, Southern Bahia, Brazil - An expression of Archean/Early Proterozoic Plate Convergence. In: VIELZEUF, D. \& VIDAL, P. eds. Granulites and Cristal Evolution. Holanda, Kluver, Academic Publishers. p. 195-221.

BARBOSA, J.S.F. 1991. Projeto Geologia e Metalogenia do Domínio da Costa Atlântica da Região Granulítica do Sul da Bahia - Brasil. Salvador, Convénio SME/SGM/UFBA/PPPG. 87 p. (Relatório

BARBOSA, J.S.F. 1992. Modelos geotectônicos do sul da Bahia. In: SIMP. REG. GEOL. BAHIA-SERGIPE, 1. Salvador, 1992. Anais... Salvador, SBG. v. 1, p. 92-95.

BARBOSA, J.S.F. \& FONTEILLES, M. 1986. Examen critique des resultats fournis par certains barometres courament utilisés en 
terrains granulitiques. Exemples des granulites de Bahia (Brésil) et du Massif de l' Agly (France). Bull. Mineral. , 109:359-376.

BARBOSA, J.S.F. \& FONTEILLES, M. 1989. Caracterização dos protólitos da região granulitica do sul da Bahia - Brasil. Rev. Brás. Geoc., 19(1):3-16

BARBOSA, J.S.F. \& FONTEILLES, M. 1992. O metamorfismo da região granulitica do sul da Bahia - Brasil. Rev. Bras. Geoc., 21(4):328-341.

BARBOSA, J.S.F.; MARINHO, M.M.; SABATE, P. 1992a. Geology of the Jequié-Itabuna Granutitic Belt. In: PEDREIRA, A. J.; MARINHO, M.M.; BARBOSA, J.S.F. eds. Petrologic and Geochronologic Evolution of the Oldest Segments of the São Francisco Craton. Salvador, IGCP. p. 7-28. (Excursion Guidebook, Project 280).

BARBOSA, J.S.F.; MARINHO, M.M.; SABATÉ, P. 1992b. Modelo geotectônico evolutivo para o embasamento da parte sudeste do Craton do São Francisco (Bahia, Brasil) In: CONGR. BRAS. GEOL., 37. São Paulo, 1992. Boletim de Resumos Expandidos... São Paulo, SBG. V. 2, p. 170-171.

BARKER, F. \& ARTH, J.G. 1976. Generation of trondhjemitic-tonalitic liquids and archean bimodal trondhjemite-basalt suites. Geology, 4:596-600

BRITO NEVES, B.B.; CORDANI, U.G.; TORQUATO, J.R.F. 1980. Evolução Geocronológica do Precambriano do Estado da Bahia. Salvador, SME/CPM/GRM-BA. p. 1-101. (Textos Básicos 3).

CONCEIÇÃO, H.; BARBOSA, J.S.F; AILLON, M.P. 1991. O Maciço Sienítico de São Félix: Petrologia e implicações geodinâmicas. In: CONGR. BRAS. GEOQ., 3. São Paulo, 1991. Anais... São Paulo, SBGq. v. 1, p. 134-138.

CORDANI, U.G. 1973. Evolução Geológica Precambriana da Faixa Costeira do Brasil, entre Salvador e Vitória. São Paulo. 98 p. (Tese de Livre Docência, IG-USP)

CORDANI, U.G. \& IYER, S.S. 1979. Geochronological investigation of the precambrian granulitic terrain of Bahia, Brazil. Precambrian Res., 9(3/4):255-274.

COSTA, L.A.M. \& MASCARENHAS, J.F. 1982. The high-grade metamorphic terrains in the interval Mutuipe-Jequié: Archean and Lower Proterozoic of east-central Bahia. In: INTERN. SYMP. ARCHEAN AND EARLY PROTEROZOIC GEOLOGIC EVOLUTION AND METALLOGENESIS. Salvador, 1982. Abstracts and Excursions... Salvador, v. 1, p. 19-37.

CRUZ, MJ. 1989. Le Massif du Rio Piauí: une Intrusion de Nature Gabbroique et Anorthositique dons les Terrains Granulitiques du Noyau Jequié-Bahia-Brésil. Paris. 277 p. (Tese de Doutoramento, Université Pierre etMarie Curie, Paris VI).

DELHAL, J. \& DEMAIFFE, D. 1985. U-Pb Archean geochronology of the São Francisco Craton (Bastem Brazil). Rev. Bras. Geoc., 15(1):55-60.

DOSTAL, J.; ZENTILLI, M.; CAELLES, J.C.; CLARK, A.H. 1977. Geochemistry and origin of volcanics rocks of the Andes $\left(26^{\circ}-28^{\circ} \mathrm{S}\right)$. Contrib. Mineral. Petrol., 63:113-128.

FIGUEIREDO, M.C.H. 1989. Geochemical evolution of eastern Bahia, Brazil: A probable Early Proterozoic subduction-related magmatic are. J. South Am. Earth Sci., 2:131-145.

FIGUEIREDO, M.C.H. \& BARBOSA, J.S.F. 1992. Terrenos metamórficos de alto grau do Craton do São Francisco. In: DOMINGUEZ, J.M.L.; MISI, A.; SABATÉ, P. eds. O Craton do São Francisco. Salvador, SBG. p. 63-84. (Publicacão Especial)

FORNARI, A. \& BARBOSA, J.S.F. 1992a. A suíte enderbitica-charnockítica da Região de Mutuipe-Bahia. In: SIMP. REG. GEOL. BAHIASERGIPE, 1. Salvador, 1992. Anais... Salvador, SBG. v. 1, p. 87-91.

FORNARI, A. \& BARBOSA, J.S.F. 1992b. Geologia, petrografia e litogeoquímica das rochas granulíticas da região de Laje e Mutuípe Bahia. In: CONGR. BRAS. GEOL., 37. São Paulo, 1992. Boletim de Resumos Expandidos... São Paulo, SBG. v. 2, p. 44-45.

GOMES, R.A.A.D.; ARCANJO, J.B.A.; SANTOS, R.A. 1991. Colisão de blocos com subducção na costa sul da Bahia. In: INTERN. CONGR BRAZIL. GEOPH. SOC., 2. Salvador, 1991. Extended Abstracts. . Salvador, SBGf, v. 1, p. 154-159.

IYER, S.S.; CHOUDHURI, A.; VASCONCELOS, M.B.A.; CORDANI, U.G. 1984. Granulite facies rocks of Brazil: are view of their geologic setting, geochronological evolution, petrographic and geochemical characteristics. J. Geol. Soc. índia, 29:309-326. IYER, S.S.; BARBOSA, J.S.F.; CHOUDHURI, A.; KROUSE, H.R. 1995. Possible sources of $\mathrm{CO}_{2}$ in granulite facies rocks: carbon isotope evidence from the Jequié Complex, Brasil. Petrology, 3:226-237

LIMA, M.C.; FONSECA, E.G.; OLIVEIRA, E.P.; GHIGNONE, J.I.; ROCHA, R.M.; CARMO, U.F.C.; SILVA, J.M.R.; SIGA, O., Jr. 1982 Folha SD-24 Salvador. Rio de Janeiro, Projeto RADAMBRASIL. 620 p. (Levantamento de Recursos Naturais).

MARINHO, M.M. 1991. La Sequence Volcano-Sedimentaire de ContendasMirante et la Bordure Occidentale du Bloc de Jequié (Craton du São Francisco, Brésil): un Exemple de Transition Archeen-Proterozoic. France. 327 p. (Tese de Doutoramento, Université Clermont-Ferrand).

MARINHO, M.M.; VIDAL, P; ALIBERT, C.; BARBOSA, J.S.F.; SABATE, P. 1992. Geochronology of the Jequié-Itabuna Granulitic Belt and Contendas-Mirante Volcano-Sedimentary Belt. In: PEDREIRA, A.J.; MARINHO, M.M.; BARBOSA, J.S.F. eds. Petrologic and Geochronologic Evolution of the Oldest Segments of the São Francisco Craton, Brazil. Salvador, IGCP. p. 57-75. (Excursion Guidebook, Project 280).
MASUDA, A.; NAKAMURA, N.; TANAKA, T. 1973. Fine structures of mutually normalized rare earth patterns of chondrites. Geochim. Cosmochim. Acta, 37(2):239-248.

MIRANDA, L.L.F.; SOARES, J.V.; MORAES, A.M.V. 1982. Geologia da região de Ubaira-Santa Inês. In: CONGR. BRAS. GEOL., 32. Salvador, 1982. Anais... Salvador, SBG. v. 1, p. 246-259.

MIRANDA, L.L.F.; SOARES, J.V.; CRUZ, J.M.; MORAES, A.M.V. 1985. Projeto Ubaira-Santa Inês. Salvador, SME/CBPM. 136 p. (Relatório Final 1).

MORRISON, G.W. 1980. Characteristics and tectonic setting of the shoshonite rock association. Lithos, 13:97-108.

OLIVEIRA, E.P. \& LIMA, M.I.C. 1982. Aspectos petroquímicos das rochas granulíticas do Complexo de Jequié e estimativas das condições físicas do metamorfismo. In: CONGR. BRAS. GEOL., 32. Salvador, 1982. Anais... Salvador, SBG. v. 2, p. 589-602.

OLIVEIRA, E.P.; LIMA, M.I.C.; CARMO, U.F.; WERNICK, E. 1982. The archean granulite terrain from east Brazil. Rev. Bras. Geoc., 12(1-3):356-368.

PADILHA, A.V; SANTOS, R.A.; MARTINS, A.A.M.; ARCANJO, J.B.A.; OLIVEIRA, J.E.; GOMES, R.A.A.D. 1990. O Ciclo Jequié no Sudeste da Bahia: uma colisão arco de ilhas - continente no Arqueozóico Superior. In: CONGR. BRAS. GEOL., 36. Natal, 1990. Boletim de Resumos... Natal, SBG. v. 1, p. 345

PEARCE, J. A. 1975. Basalt geochemistry used to investigate past tectonic environments on Cyprus. Tectonophysics, 25:41-67.

PEARCE, J.A. 1976. Statistical analysis of major elements patterns in basalts. J. Petrol., 1(17): 15-43.

PEARCE, J.A. \& CANN, J.R. 1973. Tectonic settings of basic volcanic rocks determined using trace element analyses. Earth Planet. Sci. Lett.,2(19):290-300.

PECCERILLO, A. \& TAYLOR, S.R. 1976. Geochemistry of eocene calcalkaline volcanic rocks from the Kastamonu area, northern Turkey. Contrib. Mineral. Petrol., 58(1):63-81.

PEDREIRA, A.J.; ARCANJO, J.B.A.; PEDROSA, C.J.; OLIVEIRA, J.E.; SILVA, B.C.E. 1975. Projeto Bahia - Geologia da Bacia de Rio de Contas. Salvador, DNPM/CPRM. 112 p. (Relatório 3).

RAPELA, C.W. \& CAMINOS, R. 1987. Geochemical characteristics of the Upper Paleozoic magmatism in the Eastern sector of the North Patagonian Massif. Rev. Bras. Geoc., 17(4):535-543.

RIBEIRO, A.F. 1982. Projeto Manganês Valença-Gandu. Salvador, Conv. SME/CBPM. 95 p. (Relatório Final 1).

SÁ, J.H.S. \& BARBOSA, J.S.F. 1990. Origem dos depósitos de barita de Piraí do Norte. In: CONGR. BRÁS. GEOL., 36. Natal, 1990. Boletim de Resumos... Natal, SBG. v. 1, p. 122.

SIGHINOLFI, G.P. 1970. Investigation into the deep levels ofthe continental crust: petrology and chemistry of granulite facies terrains of Bahia (Brazil). Att. Soc. Tosc. Sci. Nat. Mem., Serie A. 77:327-341.

SIGHINOLFI, G.P. 1971. Investigation into deep crustal levels: fractionating effects and geochemical trends related to high-grade metamorphism. Geochim. Cosmochim. Acta, 35:1005-1021.

SIGHINOLFI, G.P. \& SAKAI, T. 1977. Uranium and thorium in archean granulite facies terrains of Bahia (Brazil). Geochem. J., 11:33-39.

SIGHINOLFI, G.P; FIGUEIREDO, M.C.H.; FYFE, W.S.; KRONBERG, B.I.; OLIVEIRA, M.A.F. 1981. Geochemistry and petrology of the Jequié Granulitic Complex (Brazil): An Archean basement complex. Contrib. Mineral. Petrol., 78:263-271.

SILVA, L.C. 1991. Geoquímica, Petrologia e Evolução dos Granulitos Depletados e Não-Depletados da Bahia. Brasília. 143 p. (Dissertação de Mestrado, IG-UnB).

STRECKEISEN, H.L. 1976. To each plutonic rock its proper name. Earth. Sci. Rev., 12:1-33.

TARNEY, J.; SKINNER, A.C.; SHERATON, J.W. 1972. A geochemical comparison of major Archean gneiss units from Northwest Scotland and East Greenland. In: INTERN. GEOL. CONGR., 24. Montreal, 1972. Proceedings... Montreal, v. 1, p. 162-174.

TEGYEY, M. 1979. Utilization de la Geochemie-Majeurs Pour la Cartographie des Terrains Cristallins: Possibilites des Traitement Authomatique des Analyses au BRGM. Paris, BRGM. p. 134

WILSON, N. 1987. Combined Sm-Nd, Pb/Pb and Rb-Sr Geochronology and Isotope Geochemistry in Polymetamorphic Precambrian Terrains: Examples from Bahia - Brazil and Channel Island, U.K. Inglaterra. 92 p. (Master Thesis, University of Oxford).

WILSON, N.; MOORBATH, S.; TAYLOR, P.N.; BARBOSA, J.S.F. 1988. Archean and early proterozic crustal evolution in the São Francisco Craton, Bahia, Brazil. Chem. Geol, 70(1/2): 146

XAVIER, R.P.; BARBOSA, J.S.F.; IYER, S.S.; CHOUDHURI, A.; VALARELLI, J.V; CORDANI, U.G. 1989. Low density carbonic fluids in the archean granulite facies terrain of the Jequié Complex, Bahia, Brazil. J. Geol, 97:351-359.

YANG, C. 1985. On specialization of granitoids of different genetic types in South China. The Crust the Significance of Gneisses in the Lithosphere. Athens, Theophrastus Publication S.A. p. 365-387.

MANUSCRITO A758

Recebido em 15 de abril de 1993 Revisão do autor em 4 de agosto de 1993 Revisão aceita em 4 de agosto de 1994 